\title{
Are Stocks Riskier over the Long Run? Taking Cues from Economic Theory*
}

\author{
Doron Avramov \\ Hebrew University of Jerusalem and Chinese University of Hong Kong \\ Scott Cederburg \\ University of Arizona \\ Katarína Lučivjanská \\ Pavol Jozef Šafárik University in Košice
}

\begin{abstract}
We study whether stocks are riskier or safer in the long run from the perspective of Bayesian investors who employ the long-run risk, habit formation, or prospect theory models to form prior beliefs about return dynamics. Economic theory delivers important guidance for long-run investment opportunities. Specifically, incorporating prior information from the habit formation or prospect theory models reinforces beliefs in mean reversion and inferences that stocks are safer over longer horizons. Conversely, investors with long-run risk priors perceive weaker mean reversion and riskier equities. Model-based information is particularly important for inferences about uncertainty in the dividend growth component of returns. (JEL C11, G11, G12)
\end{abstract}

\footnotetext{
*We thank Stijn Van Nieuwerburgh (the editor), two anonymous referees, John Cochrane, Thomas Dangl, Anisha Ghosh, Stefano Giglio, Gregor Kastner, Chris Lamoureux, Michael O’Doherty, Ľuboš Pástor, Rick Sias, and participants at the Eastern Finance Association Meeting, the European Finance Association Meeting, the Northern Finance Association Meeting, the Slovak Economic Association Meeting, and the Workshop on Asset Allocation under Parameter Uncertainty for helpful comments. Avramov gratefully acknowledges support from the Israel Science Foundation (grant no. 233/14) and Lučivjanská gratefully acknowledges support from the Slovak Scientific Grant Agency (VEGA grant no. 1/0344/14) and the Slovak Research and Development Agency (contract no. APVV-14-0357). All errors are our own. Send correspondence to Scott Cederburg, University of Arizona, McClelland Hall 315R, Tucson, AZ 85721; telephone: (520) 621-1716. Email: cederburg@email.arizona.edu.
} 
Whether stocks are safer or riskier over the long run is of much interest to institutions with long investment horizons such as pension funds and endowments, to financial advisers and their clients, and to management firms offering target-date retirement funds, among others. Despite its importance, this question is relatively under-researched by academic scholars and practitioners. The existing body of work reveals research controversy. In particular, when returns are independently and identically distributed (i.i.d.) and parameters governing the return dynamics are known, the annualized variance of future returns does not change with the investment horizon (e.g., Merton 1971). Departing from the i.i.d. setup, the presence of mean reversion in stock returns leads to the popular advice that long-horizon investors should overweight stocks (e.g., Siegel 2007). Given mean reversion, risk diminishes with longer investment horizons even in the presence of parameter uncertainty, as shown by Barberis (2000). Recently, Pástor and Stambaugh (2012) account for an additional source of uncertainty about risk for the long run, namely uncertainty about the current value of the expected stock return, and conclude that stocks are actually riskier over longer holding periods.

This paper studies the risk of stocks over long holding periods while incorporating the predictions of economic theory for the stock return process. Prior work largely relies on historical data to make inferences about long-horizon variance (a reduced-form approach). An inherent issue with this approach is that a very long historical record is required to make sharp inferences about risk over long horizons. In this context, asset pricing theory could provide additional guidance about important aspects of the return process for which the sample evidence is not particularly informative. We develop and apply a framework to study long-horizon variance while accounting for the predictions of the long-run risk (Bansal and Yaron 2004), external habit formation (Campbell and Cochrane 1999), and prospect theory (Barberis, Huang, and Santos 2001) models.

Each of these consumption-based models has been successful in capturing salient time-series and cross-sectional features of asset prices. ${ }^{1}$ Although it is difficult to directly test the implications of

\footnotetext{
${ }^{1}$ Extensive work demonstrates these models' ability to match time-series patterns in asset prices, such as the levels of the equity premium and risk-free rate, excess volatility, and return predictability (e.g., Wachter 2006; Bansal, Dittmar, and Kiku 2009; Kaltenbrunner and Lochstoer 2010; Bonomo et al. 2011; Bansal, Kiku, and Yaron 2012), as well as cross-sectional patterns, such as the value, credit risk, and momentum effects (e.g., Bansal, Dittmar, and Lundblad 2005; Barberis and Huang 2008; Avramov, Cederburg, and Hore 2011; Ai and Kiku 2013; Barberis,
} 
the models for long-run return dynamics, their success in matching these aspects of the data lend them credibility in this setting. The underlying assumptions in the long-run risk, habit formation, and prospect theory models about preferences and economic dynamics as well as the resulting return dynamics are quite different, which leads to interesting implications for long-horizon variance. In addition, our analysis incorporates a nonnegativity restriction on the equity premium as proposed by Campbell and Thompson (2008) and Pettenuzzo, Timmermann, and Valkanov (2014). This economic constraint has been shown to improve out-of-sample forecasting performance and sharpen estimates of model parameters. Incorporating a nonnegative equity premium is novel in the context of long-horizon return variance.

We study the risk of investing in stocks by examining the predictive return variance over various investment horizons. Predictive variance is typically computed (e.g., Avramov 2002) based on the vector autoregression (VAR) framework of Campbell and Shiller (1988), Kandel and Stambaugh (1996), Campbell and Viceira (1999), and Barberis (2000), among others. Our Bayesian investors consider long-horizon risk in the context of a VAR with stock returns, dividend growth, and model-implied state variables from the long-run risk, habit formation, or prospect theory models. Specifically, the investors form prior beliefs about the VAR parameters based on asset pricing model implications. They also allow for the possibility of model misspecification, such that prior uncertainty about the VAR parameters remains. Finally, the investors combine information from the model-based prior and historical data to make inferences about long-horizon predictive variance.

Incorporating model-based prior information can potentially improve inferences about risk over long horizons. As noted earlier, the perceived long-horizon return variance crucially depends on the return dynamics implied by the VAR. It has long been recognized that incorporating prior information into VARs improves the quality of prediction. In the macroeconomics literature, Litterman (1986) and Todd (1984) demonstrate improved predictions by Bayesian VARs with the "Minnesota" prior, and Ingram and Whiteman (1994), Del Negro and Schorfheide (2004), and Del Negro et al. (2007) incorporate model-based priors that further improve performance. In asset allocation, Avramov (2004) shows that conditional mean-variance strategies based on both data Mukherjee, and Wang 2016; Wang, Yan, and Yu 2017; Meng and Weng forthcoming). 
and factor models outperform strategies based on either the model or data alone. In our context, predictive performance may improve by shrinking the posterior distribution of the VAR parameters toward values implied by equilibrium return dynamics. To the extent that economic theory can capture aspects of future return dynamics, a Bayesian investor may form more accurate views on long-horizon variance.

In addition to informing the investor about the nature of long-run return dynamics, model-based prior information reduces the estimation risk component of predictive variance. Estimation risk arises in a Bayesian setting due to uncertainty about the VAR parameters, and it increases the perceived riskiness of stocks with the strongest effects occurring at long horizons. Introducing prior information leads to more precise parameter estimates, which tends to reduce estimation risk and decrease predictive variance for all investment horizons.

We first analyze the implications of the model-based priors from the long-run risk, habit formation, and prospect theory models for predictive return variance. Investors who form beliefs based on the habit formation or prospect theory models perceive a substantial negative effect of mean reversion on predictive variance, whereas the long-run risk investor infers a weaker effect. These findings reflect the underlying model mechanisms. The habit formation and prospect theory models generate return dynamics through time variation in effective risk aversion in economies with i.i.d. cash flows, which generates substantial mean reversion. In the long-run risk model, on the other hand, much of the variation in returns is produced by time-varying expected dividend growth, and these shocks do not contribute to mean reversion. Positive effects on predictive variance from uncertainty about future expected returns and estimation risk outweigh mean reversion for the long-run risk model, such that the annualized variance at a horizon of 20 years (50 years) is about 1.13 (1.48) times the one-year variance. In contrast, mean reversion dominates in the habit formation and prospect theory models, such that stocks appear to be quite safe at long horizons. Quite remarkably, at a 20-year (50-year) horizon, the habit formation and prospect theory investors perceive the annualized variance to be 0.74 and 0.60 (0.82 and 0.62) times the one-year variance, respectively.

We next consider investors who estimate a predictive VAR using historical data with uninforma- 
tive priors. Consistent with the previous literature, we show that mean reversion has a substantial negative effect on predictive variance under uninformative priors. Mean reversion is only partially offset by the positive effects of uncertainty about future expected returns and estimation risk for horizons up to 50 years, such that per-period variance is lower than one-period variance. For example, the annualized variance at a horizon of 20 years is about 0.75 times the one-year variance. This finding is consistent with the conventional wisdom that stocks appear to be less risky for long-horizon investors in the absence of additional information from economic theory.

Investors who consider information from both the historical data and an asset pricing model come to differing conclusions about the long-horizon riskiness of stocks depending on which model informs their beliefs. Whereas habit formation and prospect theory investors strengthen their beliefs about substantial mean reversion in returns, a long-run risk investor perceives a much smaller reduction in variance from this channel. Further analysis shows that investors remain highly uncertain about the role of mean reversion after observing the historical data, such that prior information has a strong impact on posterior beliefs. Incorporating information from model-based priors also produces a meaningful reduction in estimation risk. At a 50-year horizon, the annualized contribution of estimation risk to predictive variance under model-based priors is reduced by $8 \%$ to $16 \%$ of the one-year variance level relative to investors with uninformative priors. Taking all of these forces into account, the long-run risk investor concludes that stocks are as risky or somewhat riskier over long horizons with per-period variance of 1.01 times the one-year variance at a 50-year horizon. In stark contrast, the habit formation and prospect theory investors perceive stocks to be quite safe, and the annualized variance at a 50-year horizon is 0.59 and 0.62 times the one-period variance for the habit formation and prospect theory models, respectively.

We further investigate the nature of our results by decomposing predictive return variance into components related to dividend growth, dividend income, and changes in the market pricedividend ratio. This analysis is based on the implications of the Campbell and Shiller (1988) return decomposition, which is used in recent studies to improve return predictability inferences (e.g., Cochrane 2008; Lettau and Van Nieuwerburgh 2008). To our knowledge, we are the first to implement it in the context of predictive return variance. The evidence shows that investors 
who consider information from both an asset pricing model and historical data reach different conclusions about predictive return variance primarily because of inferences about the dividend growth component. The long-run risk, habit formation, and prospect theory models produce similar predictions for the components of return variance related to changes in the price-dividend ratio and cumulative dividend income, and these effects are muted relative to the data-based results with uninformative priors.

We find that cumulative dividend growth is highly uncertain for investors who learn from the long-run risk model due to evidence of time-varying expected dividend growth in both the model and the data. In contrast, investors with habit formation and prospect theory priors believe that long-horizon dividend growth is relatively safe, which is influenced by the i.i.d. dividend growth assumptions in these models. As a result, stocks appear to be quite safe for habit formation and prospect theory investors, whereas long-run risk investors perceive stocks to be riskier over long holding periods.

Our study is closely related to the important work of Pástor and Stambaugh (2012). Focusing on the predictive system framework of Pástor and Stambaugh (2009), the authors place informative priors directly on the degree of return predictability, the persistence of the equity premium, and the correlation between shocks to the market return and market risk premium. Their approach has the merit of explicitly specifying prior beliefs about important aspects of return dynamics. In our approach that draws on economic theory, priors for these features of return dynamics are implicit. Cochrane (2008) notes that return predictability, equity premium persistence, and the correlation between returns and changes in expected returns are jointly related through the Campbell and Shiller (1988) decomposition. For instance, valuation effects likely produce a negative correlation between current stock returns and changes in the equity premium, and a given level of correlation can be consistent with relatively strong (weak) return predictability combined with a less (more) persistent equity premium. Our approach enforces these interrelations and focuses the prior distribution on parameter values that are jointly consistent with valuation relations, as our priors are developed explicitly from valuation-based models. Put differently, Pástor and Stambaugh (2012) directly place priors on return dynamics that indirectly produce priors for the joint dynamics of re- 
turns and valuations, whereas we undertake the reverse approach of developing priors about return dynamics using the implications of valuation-based models. Altogether, we view the approaches as complementary.

Although both Pástor and Stambaugh (2012) and our study have specifications suggesting that stocks may be riskier over long horizons, the mechanisms are different. Pástor and Stambaugh (2012) account for the effects of imperfect predictors of the equity premium using a predictive system approach. Such imperfection affects predictive variance directly by introducing uncertainty about the current expected return and indirectly through other components of predictive variance. Our result that long-horizon variance is high for long-run risk investors is primarily driven by the effect of the model-based prior beliefs on the magnitude of mean reversion. The relatively weak statistical evidence of mean reversion from the data is reflected by the importance of prior beliefs. Incorporating predictor imperfection into a setting with model-based priors is likely to increase the predictive variance relative to our findings, and we leave this important issue for future research.

Our study contributes to the literature along multiple fronts. First, we extend the long-horizon variance literature by assessing the implications of priors based on asset pricing theory. Studying model-based priors in the context of investment opportunities relates to a large body of work including Black and Litterman (1992), Pástor and Stambaugh (1999, 2000, 2002a,b), and Avramov (2004). In these studies, factor models, such as the CAPM of Sharpe (1964) and Lintner (1965) and the Fama and French (1993) three-factor model, are considered to potentially reduce the errors in estimating mean returns. Moreover, each of these studies focuses on a single-period mean-variance investment paradigm. Here, we assess predictive variance as opposed to forecasting returns, and we consider a long investment horizon. Our study is also a natural complement to the return predictability literature. We incorporate three features into our analysis that have been shown to improve return forecasts: (i) informative priors, (ii) a nonnegativity constraint on the equity premium, and (iii) parameter restrictions from the Campbell and Shiller (1988) valuation relation. ${ }^{2}$

\footnotetext{
${ }^{2}$ See, e.g., (i) Kandel and Stambaugh (1996), Avramov (2002, 2004), Avramov and Wermers (2006), Pástor and Stambaugh (2009), Wachter and Warusawitharana (2009), Tu and Zhou (2010), Shanken and Tamayo (2012), and Kruttli (2016), (ii) Campbell and Thompson (2008) and Pettenuzzo, Timmermann, and Valkanov (2014), and (iii) Cochrane (2008), Lettau and Van Nieuwerburgh (2008), Binsbergen and Koijen (2010), and Koijen and Van Nieuwerburgh (2011).
} 
Given that inferences about long-horizon variance are dependent on return predictability, any forecasting improvements can translate into better views on long-horizon investment opportunities in general and predictive variance in particular.

\section{Model for Long-Horizon Variance}

We introduce our framework for modeling long-horizon variance and incorporating information from a given asset pricing model. We assess the implications of asset pricing models for the riskiness of equity over long investment horizons under multiple scenarios in which an investor uses information from (i) historical data, (ii) an asset pricing model, and (iii) both the data and a model.

\subsection{Predictive vector autoregression specification}

We adopt a vector autoregression (VAR) approach that is commonly used in the predictability literature to model stock return dynamics (e.g., Kandel and Stambaugh 1996; Campbell and Viceira 1999; Barberis 2000). In particular, our VAR model is given by

$$
\left[\begin{array}{c}
r_{t+1} \\
\Delta d_{t+1} \\
p_{t+1}-d_{t+1} \\
z_{t+1}
\end{array}\right]=a+B\left[\begin{array}{c}
p_{t}-d_{t} \\
z_{t}
\end{array}\right]+\epsilon_{t+1}, \quad \epsilon_{t+1} \sim N(0, \Sigma)
$$

In the predictive VAR, $r_{t+1}$ is the log stock market return, $\Delta d_{t+1}=d_{t+1}-d_{t}$ is $\log$ dividend growth, $p_{t+1}-d_{t+1}$ is the log price-dividend ratio, and $z_{t+1}$ is an additional model-specific state variable described later. We denote the set of VAR parameters as $\theta \equiv(a, B, \Sigma)$. Valuation ratios, such as the price-dividend ratio and the dividend yield, are commonly used predictive variables in the empirical return predictability literature (e.g., Fama and French 1988; Cochrane 2008), and each of the asset pricing models we consider generates endogenous joint dynamics for stock market valuation, expected stock returns, and realized stock returns. The price-dividend ratio is thus a primary predictor of the time-varying expected returns in these models. We also specify 
an additional $z_{t+1}$ predictor based on the implications of each asset pricing model. As discussed in Section 3, the long-run risk model predicts that the risk-free rate is a useful state variable for forecasting returns and dividend growth, whereas the prospect theory and habit formation models imply nonlinear relations between expected stock returns and the price-dividend ratio.

The joint dynamics of returns, dividends, and the price-dividend ratio are constrained by valuation relations. Cochrane (2008), Lettau and Van Nieuwerburgh (2008), Binsbergen and Koijen (2010), and Koijen and Van Nieuwerburgh (2011) use information from the Campbell and Shiller (1988) approximation of the return equation,

$$
r_{t+1}=\rho\left(p_{t+1}-d_{t+1}\right)-\left(p_{t}-d_{t}\right)+\Delta d_{t+1}+q
$$

in which $\rho$ and $q$ are log-linearization constants, to make advances in the return predictability literature. Equation (2), in conjunction with the VAR specification in Equation (1), imposes restrictions on the VAR parameters. In particular, the intercepts, slope coefficients, and covariance matrix elements associated with the return, dividend growth, and price-dividend equations are naturally linked through the valuation relation. For example, Equations (1) and (2) imply that

$\epsilon_{r, t+1}=\rho \epsilon_{p d, t+1}+\epsilon_{d, t+1}$, such that the covariance matrix elements corresponding to any of the three variables can be calculated using information from the other two variables. The intercepts and slope coefficients in Equation (1) are similarly related across the return, dividend growth, and price-dividend equations. We incorporate these implied restrictions on the VAR parameters throughout our analysis of long-horizon returns and dividend growth. Further information about the VAR restrictions is provided in the Online Appendix.

\subsection{Predictive vector autoregression estimation approach}

The first investor considered here draws information only from historical data. In this case, we estimate the VAR in Equation (1) using the standard Bayesian approach studied by Barberis (2000), who extends the seminal framework of Kandel and Stambaugh (1996), and we give this investor uninformative priors for the VAR parameters. This framework thus produces a normal- 
inverse-Wishart posterior distribution. The sample period is 1872 to 2012, which produces a long sample of 141 annual observations of stock returns, dividend growth, the price-dividend ratio, and the risk-free rate. ${ }^{3}$ We use the S\&P 500 index as the stock market proxy. Following past work, the price-dividend ratio is constructed as the current level of the index divided by the sum of total dividends paid over the most recent twelve months. All variables are in real terms.

We also study investors who make inferences about long-horizon variance within the context of an asset pricing model. As discussed earlier, asset pricing models typically imply some degree of return predictability from state variables. Investors can thus incorporate the structure implied by these models for the VAR parameters that describe the joint dynamics of returns and the state variables to learn about long-horizon variance. We implement two approaches to study the nature of asset pricing model restrictions. First, we consider the implied prior distributions of the VAR parameters for investors who form their beliefs based on an asset pricing model. Second, we allow Bayesian investors to use this model-based information as a prior while estimating the VAR with historical data.

We implement the procedure proposed by Del Negro and Schorfheide (2004) to develop modelbased prior distributions for the VAR in Equation (1). The asset pricing models that we consider generally do not have closed-form expressions for the VAR parameters, so we simulate time series of stock returns, dividend growth, the price-dividend ratio, and the implied additional state variable from each model. Conceptually, we form a model-based prior for a given model by estimating a VAR using the simulated data. To avoid stochastic variation in the implied parameters across repeated random draws from the model, we follow Del Negro and Schorfheide (2004) and replace sample moments in the VAR estimation with population moments based on 100,000 years of simulated data. Finally, we can control the strength of the prior belief to correspond to a pseudosample of $T$ annual observations from an economy driven by the model. We scale the population moments to correspond to 141 years of data, which matches the length of our empirical sample period. An investor with the model-based prior thus admits the possibility of model misspecification using this

\footnotetext{
${ }^{3}$ The data are from Robert Shiller's website at http://www. econ. yale.edu/ shiller/data.htm. We thank Robert Shiller for making the data available.
} 
approach, such that uncertainty about the VAR parameters remains. ${ }^{4}$

In addition to directly studying long-horizon variance as implied by the model-based priors, we examine investors who make use of both a model and the historical data. In this case, the investors form priors about the VAR parameters based on the predictions of the long-run risk, habit formation, or prospect theory models as described earlier and then revise their beliefs upon observing the historical data. This analysis allows us to examine how investors combine information from the data and a model, and we compare how inferences about predictive variance change relative to the cases with a single source of information. We estimate the VAR using a Bayesian procedure to produce a normal-inverse-Wishart posterior distribution of the parameters of interest. The Online Appendix contains additional details on the development of model-based priors and the estimation approach.

Finally, we study the risk of stocks over long horizons while incorporating a constraint that the market risk premium is nonnegative. This constraint is economically motivated by the notion that a risk-averse representative investor is likely to require a positive risk premium for stocks. Pettenuzzo, Timmermann, and Valkanov (2014) note that imposing a nonnegativity constraint in return forecasting regressions provides benefits for learning about parameters and reducing parameter uncertainty. Further, Campbell and Thompson (2008) and Pettenuzzo, Timmermann, and Valkanov (2014) document that the constraint improves equity premium forecasts in empirical tests. The asset pricing models we consider also rule out the possibility of a negative equity premium. However, the investors with model-based priors admit the possibility of model misspecification, such that nonnegativity is not strictly enforced by the model-based prior. In our empirical tests, we introduce an additional constraint for investors with model-based priors to enforce this nonnegativity restriction. Whereas the literature studies short-term return predictability in the presence of a nonnegativity constraint, assessing the riskiness of equity in the long run in this setting is novel. ${ }^{5}$

Following Pettenuzzo, Timmermann, and Valkanov (2014), the nonnegativity restriction can

\footnotetext{
${ }^{4}$ Allowing for potential model misspecification could be a natural response of investors to evidence in the literature against certain assumptions or implications of an asset pricing model (e.g., Beeler and Campbell 2012; Yu 2012; Bidder and Smith 2015).

${ }^{5}$ We examine versions of the VARs that are estimated without a nonnegativity constraint in the Online Appendix.
} 
be implemented in a Bayesian setting by rejecting any posterior draw that produces a negative predicted value for the equity premium in any period. The constraint thus depends on forecasts of expected excess market returns. Each VAR produces market return forecasts, and the VAR for the long-run risk model also implies a fitted real risk-free rate. The habit formation and prospect theory model VARs do not include a real risk-free rate, so we estimate a separate Bayesian predictive regression to develop expected real risk-free rates. ${ }^{6}$ To implement the nonnegativity constraint, we reject the posterior draws in which the difference between the forecasted market return and risk-free rate is negative in any period.

\section{What Happens over Long Horizons?}

Our primary focus is studying stock return volatility over long horizons from an investor's perspective. Similar to Barberis (2000) and Pástor and Stambaugh (2012), we focus on the ex ante Bayesian predictive variance rather than the ex post realized variance. The Bayesian predictive variance conditions only on information available to investors and thus accounts for parameter uncertainty in the forward-looking variance forecast. Per-period variance is crucial in making longhorizon investment decisions, so the shape of the volatility curve over alternative horizons is an important consideration for multiperiod investors. For instance, Barberis (2000) and Siegel (2007) contend that variance decreases with horizon and advocate higher allocations to equity over long investment horizons, whereas Pástor and Stambaugh (2012) provide evidence to the contrary.

We investigate whether the per-period predictive variance increases or decreases with the investment horizon and how the shape of the volatility curve is affected when the economic restrictions of asset pricing models are incorporated. The predictive return variance can be decomposed as follows:

$$
\operatorname{Var}\left(r_{T, T+k} \mid D_{T}\right)=\mathrm{E}\left[\operatorname{Var}\left(r_{T, T+k} \mid \theta, D_{T}\right) \mid D_{T}\right]+\operatorname{Var}\left[\mathrm{E}\left(r_{T, T+k} \mid \theta, D_{T}\right) \mid D_{T}\right]
$$

\footnotetext{
${ }^{6}$ Both the habit formation and prospect theory models imply constant risk-free rates. Matching risk-free rate dynamics was not a goal for calibrating these models, such that we rely on an empirical approach for modeling real risk-free rate expectations. Our results are robust to using the model-implied risk-free rate for the nonnegativity constraint, and this analysis is available in the Online Appendix.
} 
where $r_{T, T+k}=r_{T+1}+\ldots+r_{T+k}$ is the cumulative log return over a $k$-year horizon, $\theta$ is the set of parameters in the predictive VAR in Equation (1), and $D_{T}$ is the data observable at time $T$. The first term corresponds to the expected variance of long-horizon returns. Given the predictive regression environment in Equation (1) with constant covariance matrix $\Sigma, \operatorname{Var}\left(r_{T, T+k} \mid \theta, D_{T}\right)=$ $\operatorname{Var}\left(r_{T, T+k} \mid \theta\right)$. Long-horizon return variance consists of three sources of uncertainty in this framework, ${ }^{7}$

$$
\begin{aligned}
\operatorname{Var}\left(r_{T, T+k} \mid \theta\right) & =k \sigma_{r}^{2}+\sum_{i=1}^{k-1} 2 b_{r}\left(I-B_{x}\right)^{-1}\left(I-B_{x}^{i}\right) \Sigma_{x r} \\
& +\sum_{i=1}^{k-1}\left(b_{r}\left(I-B_{x}\right)^{-1}\left(I-B_{x}^{i}\right)\right) \Sigma_{x}\left(b_{r}\left(I-B_{x}\right)^{-1}\left(I-B_{x}^{i}\right)\right)^{\prime}
\end{aligned}
$$

where $x_{t} \equiv\left[\begin{array}{ll}p_{t}-d_{t} & z_{t}\end{array}\right]^{\prime}$ and the components of the $B$ and $\Sigma$ parameters in Equation (1) are written as follows:

$$
B \equiv\left[\begin{array}{c}
b_{r} \\
b_{d} \\
B_{x}
\end{array}\right]
$$

and

$$
\Sigma \equiv\left[\begin{array}{ccc}
\sigma_{r}^{2} & \sigma_{r d} & \Sigma_{x r}^{\prime} \\
\sigma_{r d} & \sigma_{d}^{2} & \Sigma_{x d}^{\prime} \\
\Sigma_{x r} & \Sigma_{x d} & \Sigma_{x}
\end{array}\right]
$$

The first term in Equation (4) can be interpreted as the uncertainty from i.i.d. shocks and contributes the same per-period variance at all horizons. The second component reflects the meanreverting dynamics of expected returns, and this term is negative and decreases with horizon $k$ given typical parameter estimates. The effect of mean reversion on the long-horizon variance of returns is heavily discussed in the literature and is commonly considered to be a primary driver of the shape of the long-horizon variance curve. Due to this effect, it is often believed that stocks have lower per-period variance and are less risky for long-horizon investors.

A third component of variance that corresponds to uncertainty about future expected returns

\footnotetext{
${ }^{7}$ The derivation can be found in the Online Appendix and Avramov (2002).
} 
increases with the horizon. Even given the model parameters and current values of the predictors, we are still uncertain about future expected returns (or, equivalently, about the future values of the predictors) in each period. This uncertainty generates additional predictive variance for stock returns that is often ignored in the literature. Given that mean reversion can only occur if expected returns are time varying, this uncertainty component of variance will always offset at least a portion of the effect of mean reversion. In fact, either component could dominate such that it is not obvious (prior to studying the data) whether long-horizon variance is higher or lower for different horizons.

Finally, an additional component of predictive variance emerges in a Bayesian framework - the estimation risk component. In Bayesian econometrics, parameters are uncertain and the predictive distribution integrates over the parameter space, thereby giving rise to the estimation risk component. This component, generated by the second term of the predictive variance in Equation (3), is the posterior variance of the expected long-horizon return implied by the VAR. The expected long-horizon return, $\mathrm{E}\left(r_{T, T+k} \mid \theta, D_{T}\right)=\mathrm{E}\left(r_{T, T+k} \mid \theta, x_{T}\right)$, is given by

$$
\mathrm{E}\left(r_{T, T+k} \mid \theta, x_{T}\right)=k a_{r}+b_{r}\left(I-B_{x}\right)^{-1}\left(\left(k I-\left(I-B_{x}\right)^{-1}\left(I-B_{x}^{k}\right)\right) a_{x}+\left(I-B_{x}^{k}\right) x_{T}\right),
$$

where $a \equiv\left[\begin{array}{lll}a_{r} & a_{d} & a_{x}^{\prime}\end{array}\right]^{\prime}$. Since the investor is uncertain about the parameters governing expected returns, estimation risk increases the predictive return variance and the effect grows with horizon. As previously discussed, introducing model-based priors can reduce estimation risk by reducing this parameter uncertainty.

The predictive variance of stock returns in the predictive VAR framework follows from substituting Equations (4) and (7) into Equation (3). Altogether, the predictive variance consists of four 
parts:

$$
\begin{aligned}
\operatorname{Var}\left(r_{T, T+k} \mid D_{T}\right) & =\underbrace{\mathrm{E}\left(k \sigma_{r}^{2} \mid D_{T}\right)}_{\text {i.i.d. uncertainty }}+\underbrace{\mathrm{E}\left[\sum_{i=1}^{k-1} 2 b_{r}\left(I-B_{x}\right)^{-1}\left(I-B_{x}^{i}\right) \Sigma_{x r} \mid D_{T}\right]}_{\text {mean reversion }} \\
& +\underbrace{\mathrm{E}\left[\sum_{i=1}^{k-1}\left(b_{r}\left(I-B_{x}\right)^{-1}\left(I-B_{x}^{i}\right)\right) \Sigma_{x}\left(b_{r}\left(I-B_{x}\right)^{-1}\left(I-B_{x}^{i}\right)\right)^{\prime} \mid D_{T}\right]}_{\text {future expected return uncertainty }} \\
& +\underbrace{\operatorname{Var}\left[k a_{r}+b_{r}\left(I-B_{x}\right)^{-1}\left(\left(k I-\left(I-B_{x}\right)^{-1}\left(I-B_{x}^{k}\right)\right) a_{x}+\left(I-B_{x}^{k}\right) x_{T}\right) \mid D_{T}\right]}_{\text {estimation risk }} .
\end{aligned}
$$

In our empirical analysis, we calculate the predictive variance ratio $\left(\frac{\operatorname{Var}\left(r_{T, T+k} \mid D_{T}\right)}{k \operatorname{Var}\left(r_{T, T+1} \mid D_{T}\right)}\right)$ and evaluate the importance of each of the three components that vary with horizon to determine the shape of the long-horizon variance curve.

Incorporating model-based priors can affect inferences about predictive variance in two primary ways. First, introducing prior information produces more precise parameter estimates, which tends to reduce the estimation risk component in Equation (8). Second, if the sample evidence is relatively uninformative about important aspects of return dynamics, prior information may provide important guidance about the components related to mean reversion and uncertainty about future expected returns. These components are highly nonlinear functions of the underlying VAR parameters, and even a relatively small change in parameter estimates can have a large impact on these components and the resulting long-horizon variance. Thus, even if the VAR parameters are estimated reasonably precisely from the data, investors may be quite uncertain about the highly nonlinear functions of the parameters that ultimately determine the strength of mean reversion and uncertainty about future expected returns. ${ }^{8}$ Information from model-based priors thus has the potential to strongly affect investor inferences about long-horizon variance.

In addition to studying the long-horizon variance of returns, the VAR in Equation (1) produces

\footnotetext{
${ }^{8}$ In a related context, Runkle (1987) notes that multiperiod forecasts, impulse response functions, and variance decompositions from VARs in the macroeconomics literature can be highly uncertain due to the nonlinearities in these calculations.
} 
information about the long-run dynamics of dividend growth and the price-dividend ratio. The long-horizon predictive variance of cumulative dividend growth has an analogous expression to Equation (8), and the full derivation of this equation is available in the Online Appendix. Further, the valuation relation in Equation (2) implies that cumulative returns over a horizon of $k$ years can be expressed as

$$
r_{T, T+k}=\left(p_{T+k}-d_{T+k}\right)-\left(p_{T}-d_{T}\right)+\sum_{i=1}^{k}(1-\rho)\left(d_{T+i}-p_{T+i}\right)+\Delta d_{T, T+k}+k q
$$

Returns have three components that contribute to uncertainty. First, the difference between beginning and terminal price-dividend ratios, $\left(p_{T+k}-d_{T+k}\right)-\left(p_{T}-d_{T}\right)$, measures the effect of a change in market valuation on realized returns. Second, the $\sum_{i=1}^{k}(1-\rho)\left(d_{T+i}-p_{T+i}\right)$ term captures the cumulative effect of dividend income during the holding period. Third, $\Delta d_{T, T+k}$ is the cumulative dividend growth that is realized over the $k$-year horizon. Equation (9) allows us to decompose predictive return variance,

$$
\begin{aligned}
\operatorname{Var}\left(r_{T, T+k} \mid D_{T}\right) & =\operatorname{Var}\left(p_{T+k}-d_{T+k} \mid D_{T}\right)+\operatorname{Var}\left(\sum_{i=1}^{k}(1-\rho)\left(d_{T+i}-p_{T+i}\right) \mid D_{T}\right) \\
& +\operatorname{Var}\left(\Delta d_{T, T+k} \mid D_{T}\right)+2 \operatorname{Cov}\left(p_{T+k}-d_{T+k}, \sum_{i=1}^{k}(1-\rho)\left(d_{T+i}-p_{T+i}\right) \mid D_{T}\right) \\
& +2 \operatorname{Cov}\left(p_{T+k}-d_{T+k}, \Delta d_{T, T+k} \mid D_{T}\right) \\
& +2 \operatorname{Cov}\left(\sum_{i=1}^{k}(1-\rho)\left(d_{T+i}-p_{T+i}\right), \Delta d_{T, T+k} \mid D_{T}\right),
\end{aligned}
$$

and we provide expressions for these quantities as functions of the VAR parameters in the Online Appendix. This decomposition allows us to study the relative effects of dividend income, dividend growth, and changes in market valuation on uncertainty about cumulative market returns over long horizons.

Before proceeding, we note that the model-based priors are drawn from versions of the long-run risk, habit formation, and prospect theory models that are calibrated by Bansal, Kiku, and Yaron (2012), Campbell and Cochrane (1999), and Barberis, Huang, and Santos (2001), respectively. 
These studies calibrate the models to match stylized facts from historical periods that overlap with our data sample. To the extent that the asset pricing models reflect information in our historical data, both the models and the data may provide less incremental information relative to the alternative source. Our empirical sample period of 1872 to 2012 is roughly twice as long as the calibration samples in the original studies. Additionally, the models are calibrated using additional nonfinancial data such as aggregate consumption, which may help our investors to learn about long-horizon return variance by considering additional information through the lens of an equilibrium asset pricing model. Given our setup, both the models and the data may provide important incremental information about long-horizon investment opportunities.

\section{Asset Pricing Models}

The consumption-based asset pricing literature has developed several models to capture salient features of stock market returns, such as the large equity premium, high market volatility, and predictability using the price-dividend ratio. We study investor beliefs about long-horizon variance in the context of prominent asset pricing models: the long-run risk model of Bansal and Yaron (2004), the external habit formation model of Campbell and Cochrane (1999), and the prospect theory model of Barberis, Huang, and Santos (2001). These models achieve success in matching empirical facts while making different underlying assumptions about economic dynamics and investor preferences. Studying these models thus illustrates the impact of model assumptions and predictions on inferences about long-horizon variance.

\subsection{Long-run risk model}

In Bansal and Yaron's (2004) long-run risk model, the consumption and dividend growth processes feature a small persistent drift component, such that expected economic growth is time varying. Further, economic uncertainty is time varying, which produces time variation in the riskiness of stocks. These persistent components of the consumption and dividend growth processes induce correlation between the pricing kernel of an Epstein-Zin (1989) investor and the stock market 
return, which results in a high equity premium in the model. Moreover, changes in economic uncertainty produce time variation in expected stock returns and the market price-dividend ratio.

Formally, the representative investor maximizes Epstein-Zin recursive utility,

$$
U_{t}=\left[(1-\delta) \bar{C}_{t}^{1-1 / \psi}+\delta\left(\mathrm{E}_{t} U_{t+1}^{1-\gamma}\right)^{(1-1 / \psi) /(1-\gamma)}\right]^{1 /(1-1 / \psi)}
$$

in which $\bar{C}_{t}$ is aggregate consumption, $\delta$ is a time discount factor, $\gamma$ is the risk aversion parameter, and $\psi$ is the elasticity of intertemporal substitution. The aggregate log consumption and dividend growth rates, $g_{c, t+1}$ and $g_{d, t+1}$, contain a small persistent component, $g_{t}$, and a fluctuating component reflecting economic uncertainty, $\sigma_{t}$,

$$
\begin{aligned}
g_{t+1} & =\rho g_{t}+\varphi_{e} \sigma_{t} e_{t+1}, \\
g_{c, t+1} & =\mu_{c}+g_{t}+\sigma_{t} \eta_{t+1}, \\
g_{d, t+1} & =\mu_{d}+\phi g_{t}+\varphi_{d} \sigma_{t} u_{t+1}+\pi \sigma_{t} \eta_{t+1}, \\
\sigma_{t+1}^{2} & =\sigma^{2}+\nu_{1}\left(\sigma_{t}^{2}-\sigma^{2}\right)+\sigma_{w} w_{t+1},
\end{aligned}
$$

where the shocks $e_{t+1}, \eta_{t+1}, u_{t+1}$, and $w_{t+1}$ are i.i.d. and have independent standard normal distributions. To produce an equity risk premium that is consistent with the data, the Epstein-Zin investor must have preferences such that $\gamma>1 / \psi$. Under these conditions, the price-dividend ratio tends to be high when expected consumption and dividend growth rates are high due to the persistent component $g_{t}$ and when economic uncertainty $\sigma_{t}^{2}$ is relatively low.

Stock market returns in the long-run risk model are predictable using macroeconomic state variables. In particular, Constantinides and Ghosh (2011) show that the expected stock market return in the model is a linear function of the price-dividend ratio and risk-free rate. We thus include the risk-free rate as the additional state variable $z_{t}$ in the VAR in Equation (1) when analyzing the long-run risk model. We generate simulated data for excess stock returns, dividend growth, the price-dividend ratio, and the risk-free rate following Bansal, Kiku, and Yaron (2012). We simulate monthly data and aggregate the monthly observations to an annual frequency to match 
our empirical data frequency. The simulated time series is then used to estimate the model-based VAR as described in Section 1.2.

\subsection{Habit formation model}

Campbell and Cochrane's (1999) habit formation model introduces identical investors with preferences that incorporate an external habit. In particular, each agent's habit is based on historical aggregate consumption, and investors gain utility from their consumption in excess of the habit. These investors price assets within an economy with i.i.d. consumption and dividend growth. Discount rates are time varying, however, as a result of changes in the effective risk aversion of the agents. Following extended periods of low realized consumption growth, investors require higher risk premiums as consumption approaches the habit. This variation in discount rates in the model produces stock market returns that are predictable using the price-dividend ratio.

Agents in the model maximize expected utility,

$$
\mathrm{E}\left[\sum_{t+1}^{\infty}\left(\delta^{t} \frac{\left(C_{t}-H_{t}\right)^{1-\gamma}}{1-\gamma}\right)\right]
$$

in which $C_{t}$ is consumption and $H_{t}$ is an external habit level. The evolution of the habit can be described by the log surplus ratio,

$$
\bar{s}_{t}=\log \left(\frac{\bar{C}_{t}-H_{t}}{\bar{C}_{t}}\right),
$$

which measures the surplus of aggregate consumption over the habit level. The log surplus ratio follows the process

$$
\bar{s}_{t+1}=(1-\phi) \bar{s}+\phi \bar{s}_{t}+\lambda\left(\bar{s}_{t}\right)\left(\bar{c}_{t+1}-\bar{c}_{t}-g_{c}\right),
$$

in which $\phi$ and $\bar{s}$ are parameters governing the persistence and long-run mean of the log surplus ratio, $g_{c}$ is expected consumption growth, and $\lambda\left(\bar{s}_{t}\right)$ is a sensitivity function that modulates the effect of unexpected consumption growth on the habit. Aggregate consumption growth and dividend 
growth follow lognormal processes,

$$
\begin{aligned}
\log \left(\bar{C}_{t+1} / \bar{C}_{t}\right) & =g_{c}+\sigma_{c} \eta_{t+1}, \\
\log \left(\bar{D}_{t+1} / \bar{D}_{t}\right) & =g_{d}+\sigma_{d} \epsilon_{t+1},
\end{aligned}
$$

in which $\bar{D}_{t+1}$ is the aggregate dividend on stocks. The innovations $\eta_{t+1}$ and $\epsilon_{t+1}$ are i.i.d. and come from a standard bivariate normal distribution with correlation $\omega$. Finally, the consumption of the identical agents must equal aggregate consumption in equilibrium, $C_{t}=\bar{C}_{t}$.

The surplus ratio is the sole state variable that describes time variation in valuation levels and expected returns in the model. The price-dividend ratio is an increasing function of the surplus ratio, and expected returns are decreasing in the surplus of consumption over the habit level. By inversion, expected returns are thus a decreasing function of the price-dividend ratio. To account for nonlinearities in the relation between expected returns and the price-dividend ratio, we introduce a function $f\left(p_{t}-d_{t}\right)$ as the additional state variable $z_{t}$ in the VAR in Equation (1). This state variable is designed to measure the model-implied expected return, and we estimate the function using a kernel regression of returns on the price-dividend ratio using 100,000 years of simulated data from the model. We simulate monthly returns, price-dividend ratios, and dividend growth from the model following Campbell and Cochrane (1999) and Wachter (2005) and aggregate to an annual frequency. The Online Appendix provides additional details on the $z_{t}$ state variable and the associated improvements in predictability regression fit.

\subsection{Prospect theory model}

In Barberis, Huang, and Santos's (2001) prospect theory model, identical agents extract utility not only from their consumption but also from fluctuations in their financial wealth. Prospect theory investors are loss averse, as they are more concerned about losses than gains. Investors track their gains and losses relative to a slow-moving benchmark, and their effective risk aversion is higher (lower) when they have accumulated losses (gains). This specification triggers intertemporal variation in risk aversion and more volatile asset prices relative to the benchmark case with symmetric 
preferences.

Formally, prospect theory agents maximize utility of the form

$$
\mathrm{E}\left[\sum_{t+1}^{\infty}\left(\delta^{t} \frac{C_{t}^{1-\gamma}}{1-\gamma}+b_{0} \bar{C}_{t}^{-\gamma} \delta^{t+1} v\left(X_{t+1}, S_{t}, s_{t}^{*}\right)\right)\right]
$$

in which the first part of the utility function corresponds to standard power utility over the agent's consumption and the second part reflects loss aversion preferences. The $b_{0} \bar{C}_{t}^{-\gamma}$ term is a scaling factor. The function $v$ depends on the value of the agent's stock holdings $S_{t}$, the change in financial wealth $X_{t+1} \equiv S_{t} R_{t+1}-S_{t} R_{f, t}$ (where $R_{t+1}$ and $R_{f, t}$ are the returns on stocks and the risk-free asset), and $s_{t}^{*}$, which is the historical benchmark level of stocks $S_{t}^{*}$ given as a fraction of the stock value $S_{t}$ (i.e., $s_{t}^{*} \equiv S_{t}^{*} / S_{t}$ ). The state variable $s_{t}^{*}$ is assumed to evolve sluggishly and is modeled by

$$
s_{t+1}^{*}=\eta\left(s_{t}^{*} \frac{\bar{R}}{R_{t+1}}\right)+(1-\eta)
$$

in which $\bar{R}$ is a parameter chosen such that $s_{t}^{*}$ is equal to one on average and $\eta \in[0,1]$ corresponds to the memory of the agents. If $\eta=0$, the benchmark level quickly adapts and is equal to the stock price at every time $t, S_{t}^{*}=S_{t}$. When $\eta$ is greater than zero, however, the benchmark level reflects a longer memory of the agent with respect to past gains and losses. Overall, the function $v$ captures loss aversion such that agents are more sensitive to losses below their historical benchmark. Aggregate consumption and dividend growth rates follow the same i.i.d. processes as in the habit formation model (i.e., Equations (19) and (20)).

Given that dividend growth is i.i.d., all variation in the price-dividend ratio is driven through a valuation channel with time-varying expected returns. For example, the gains from an unexpected positive dividend shock reduce effective risk aversion. A corresponding decrease in expected returns is accompanied by an increase in the price-dividend ratio that amplifies the effects of dividend shocks in the model. In equilibrium, the price-dividend ratio is a decreasing function of the sole state variable $s_{t}^{*}$, whereas the expected market return is an increasing function of $s_{t}^{*}$. Similar to our approach for the habit formation model, we estimate the state variable $z_{t}$ that approximates expected returns as a nonlinear function of the price-dividend ratio using a kernel regression on 
simulated data. Our simulation follows the procedure outlined by Barberis, Huang, and Santos (2001), and we generate 100,000 annual observations of returns, dividend growth, and the pricedividend ratio.

\section{Empirical Results}

We investigate long-horizon predictive variance from the perspectives of investors who make inferences based on (i) historical data, (ii) the implications of an asset pricing model, and (iii) a combination of historical data and model-based information. We also study the impact of uncertainty about dividend growth, dividend income, and changes in market valuation on the long-run riskiness of stocks.

\subsection{Predictive vector autoregression estimates}

Tables 1 to 3 show parameter estimates for the VAR in Equation (1) corresponding to the long-run risk, habit formation, and prospect theory models, respectively. In each table, Panel A displays estimates from a data-based VAR with uninformative priors, Panel B reports the VAR parameters implied by the asset pricing model, and Panel $\mathrm{C}$ shows results from estimating the VAR using the model-based priors. Recall that the VARs include model-specific state variables, such that the models produce different VARs even under uninformative priors. Each panel reports the posterior mean for each parameter with the posterior standard deviation in parentheses. The covariance/correlation matrix contains variances along the diagonal and covariances (correlations) in the upper-right (lower-left) portion of the matrix.

Several aspects of the VARs are important for inferences about the long-horizon predictive variances of returns and dividend growth. Evidence of return predictability using the state variables has two primary effects on predictive variance. First, predictable returns contribute positively to long-horizon variance by inducing uncertainty about future expected returns. Second, if returns are predictable and the shocks to realized returns and expected future returns are negatively correlated, mean reversion produces a negative effect on predictive variance. Thus, the degree of return 
predictability and the strength of the correlation between returns and the predictive state variables are particularly important for inferences about the long-horizon risk of stocks. Similar features are important for studying cumulative dividend growth over the long run.

We begin by studying the long-run risk VARs in Table 1. Recall that the additional state variable, $z_{t}$, in the long-run risk model is the risk-free rate. Focusing on the VAR with uninformative priors in Panel A, the parameter estimates suggest that market returns are positively predicted by the risk-free rate with a coefficient posterior mean of 0.57 and posterior standard deviation of 0.29. The positive and significant predictive ability of the risk-free rate is unsurprising given that expected market returns are the sum of the risk-free rate and expected excess return. The predictive coefficient associated with the price-dividend ratio is insignificantly different from zero at conventional levels with a posterior mean of -0.05 (standard deviation of 0.03 ).

The VAR estimates in Panel A of Table 1 suggest that shocks to returns and the price-dividend ratio are highly positively correlated at 0.82 (standard deviation of 0.03). As discussed by Barberis (2000) and Pástor and Stambaugh (2012), to the extent that the price-dividend ratio negatively forecasts returns, such positive correlation induces a negative relation between realized current returns and changes in expected future returns, which triggers mean reversion in stock returns. The correlation between stock market return and risk-free rate shocks, on the other hand, is small in magnitude at -0.04 (standard deviation of 0.09). As a result, the time variation in expected returns that is related to the risk-free rate contributes relatively little to mean reversion.

The VAR also produces implications for dividend growth. The estimates suggest that dividend growth is highly predictable using the price-dividend ratio with a predictive coefficient of 0.09 (standard deviation of 0.02), whereas the risk-free rate is not significantly related to future dividend growth. The correlation between shocks to dividend growth and the price-dividend ratio is negative at -0.49 (standard deviation of 0.07 ). As we show in Section 4.3, the combination of this negative correlation and the positive predictive coefficient on the price-dividend ratio produces some degree of anticipated mean reversion in dividend growth.

Panel B of Table 1 shows the VAR parameters for the model-based prior from the long-run risk model. Recall that the strength of the prior is set to correspond to a pseudosample of 141 annual 
observations from the model, such that prior uncertainty about the VAR parameters remains. The model implies that market returns are predictable, with a negative coefficient on the price-dividend ratio of -0.21 (standard deviation of 0.09 ) and a positive coefficient on the risk-free rate of 5.37 (standard deviation of 2.01). The positive correlation between return and price-dividend ratio shocks is 0.68 (standard deviation of 0.05), which is low compared with the data-based estimate. The economic dynamics assumed in the long-run risk model are also apparent in the model-based prior for dividend growth. In particular, the VAR implies that dividend growth is highly predictable by the price-dividend ratio with a coefficient of 0.20 (standard deviation of 0.07 ).

The results from estimating the VAR using the priors implied by the long-run risk model are in Panel $\mathrm{C}$ of Table 1. The posterior parameter estimates for return predictability suggest that the risk-free rate is a significant predictor with a coefficient of 0.65 (standard deviation of 0.17 ). The most significant role of the nonnegativity constraint on the equity premium in our analysis is its effect on return predictability using the price-dividend ratio with long-run risk priors. Without the nonnegativity constraint, the coefficient on the price-dividend ratio is -0.05 (standard deviation of 0.03 ), and the nonnegativity constraint decreases this estimate to -0.02 (standard deviation of 0.02). ${ }^{9}$ When the price-dividend ratio and the risk-free rate are included jointly as predictors, the nonnegativity constraint increases the relative importance and statistical significance of the riskfree rate predictor while downplaying the role of the price-dividend ratio. Posterior draws with a large negative predictive coefficient for the price-dividend ratio tend to imply negative expected excess returns in times with high market valuation levels, and these draws are rejected using the nonnegativity constraint. Investors with a long-run risk prior also conclude that dividend growth is highly predictable given that both the model and the data support this finding. The price-dividend ratio is a stronger predictor of dividend growth in both magnitude and statistical significance for an investor with long-run risk priors (posterior mean of 0.12 and standard deviation of 0.02) compared with the investor with uninformative priors in Panel A.

The VAR parameter estimates for the habit formation and prospect theory models appear in Tables 2 and 3, respectively. Owing to similarities in the models' assumptions of i.i.d. economic

\footnotetext{
${ }^{9}$ These results are available in the Online Appendix.
} 
growth and the pricing effects from the economic mechanism of time-varying effective risk aversion, the models have relatively similar implications for the VAR parameters. Recall that the $z_{t}$ variable for these models is the estimated expected return as a function of the price-dividend ratio. Given that model-implied expected returns are decreasing in the price-dividend ratio, the $p_{t}-d_{t}$ and $z_{t}$ state variables are negatively correlated. Further, the two variables are closely related because a linear relation between the log price-dividend ratio and future log stock market returns provides a reasonable first-order approximation to the state variable $z_{t}$.

Panel A of Table 2 contains parameter estimates for the VAR with uninformative priors and the habit formation state variables. There is weak evidence that returns are predictable using the price-dividend ratio and $z_{t}$ state variables. The coefficient estimates of -0.08 (standard deviation of 0.10 ) for the price-dividend ratio and -0.19 (standard deviation of 1.03) for $z_{t}$ are statistically insignificant. As discussed earlier, however, the two state variables are closely related, which affects the predictive coefficient estimates. Specifications that include only one of the state variables produce predictive parameter estimates of -0.06 for the price-dividend ratio and 0.52 for $z_{t}$, but the $90 \%$ credible intervals contain zero such that the results are statistically insignificant at conventional levels. The $z_{t}$ variable is a significant predictor of dividend growth with a coefficient of -1.50 (standard deviation of 0.66), implying that expected dividend growth tends to be high in periods when expected returns are low. Finally, stock returns are highly correlated with both the pricedividend ratio and $z_{t}$ state variables. ${ }^{10}$

The model-based prior for habit formation is shown in Panel B of Table 2. The two state variables are highly negatively correlated, such that neither is a statistically significant predictor of returns when both are included in the VAR. Either state variable is, however, a significant predictor of returns in isolation. Dividend growth is not predictable according to the modelbased VAR, which is consistent with the model's assumption of i.i.d. growth. The model implies a positive contemporaneous correlation between dividend growth and the price-dividend ratio of 0.20 (standard deviation of 0.08). In the model, positive dividend shocks tend to occur in periods with an unexpected increase in surplus consumption, such that the agent becomes less risk averse

\footnotetext{
${ }^{10}$ We ensure that the VAR is stationary despite the autoregressive coefficient estimate of 1.01 for the price-dividend ratio.
} 
and the stock market valuation increases in these periods. Overall, the model's implications for dividend growth in Panel B stand in contrast to the data-based evidence in Panel A.

The VAR posteriors for investors with habit formation priors are reported in Panel C of Table 3. Market returns are significantly predicted by $z_{t}$ with a coefficient of 0.95 (standard deviation of 0.33 ) after considering information from both the model and the historical data. Incorporating prior information from the habit formation model thus has the effect of increasing the investor's posterior belief that returns are predictable. Evidence of dividend growth predictability, on the other hand, is much weaker with the habit formation prior compared with the uninformative prior results in Panel A. Finally, after observing the data, the habit formation investor changes from a belief in a positive correlation between shocks to dividend growth and the price-dividend ratio to a belief that the correlation is negative at -0.24 (standard deviation of 0.06 ).

The prospect theory results in Table 3 are similar in spirit to the habit formation estimates. In particular, returns are not highly predictable using uninformative priors, but an investor who estimates the VAR with model-based priors from the prospect theory model strongly believes that returns can be predicted using the $z_{t}$ variable. The posterior evidence that dividend growth is predictable is much weaker with priors based on the prospect theory model that assumes i.i.d. growth. Finally, the prospect theory investor has a prior belief that shocks to returns, dividend growth, and the price-dividend ratio are almost perfectly correlated. In the model, dividend shocks are accompanied by changes in risk aversion, and valuation changes amplify the effects of cash-flow shocks. This investor, however, revises his or her beliefs after observing the historical data such that the correlation between shocks to dividend growth and the price-dividend ratio is nearly zero.

\subsection{Long-horizon variance with model-based priors}

Our analysis of the riskiness of stocks over long horizons is centered around variance ratios based on Bayesian predictive variances. The variance ratio for a given horizon $k$,

$$
\operatorname{VR}(k)=\frac{\operatorname{Var}\left(r_{T, T+k} \mid D_{T}\right)}{k \operatorname{Var}\left(r_{T, T+1} \mid D_{T}\right)}
$$


is the ratio of the predictive variance at horizon $k$ divided by the one-period predictive variance scaled by the horizon. A variance ratio of one at a given horizon $k$ would thus indicate that the per-period variance over a longer horizon is equal to the one-period variance, whereas variance ratios below (above) one indicate that stocks are relatively safer (riskier) at horizon $k$. We also assess the three components in Equation (8) that reflect horizon effects in return variance: mean reversion, uncertainty about future expected returns, and estimation risk. Notice that the i.i.d. component produces a constant per-period effect such that it provides a reference point for the variance ratio but does not affect the shape of the variance ratio curve.

We begin by studying the long-horizon predictive variance implied by each of the asset pricing models. Panel A of Figure 1 displays the predictive variance ratios associated with the model-based priors from the long-run risk (black solid line), habit formation (blue dashed line), and prospect theory (red dash-dot line) models over investment horizons that range from one year to 50 years. The remaining three panels show the components related to mean reversion (Panel B), uncertainty about future expected returns (Panel C), and estimation risk (Panel D). Each of these components is scaled by $k \operatorname{Var}\left(r_{T, T+1} \mid D_{T}\right)$ to demonstrate their contributions to the predictive variance ratio.

The models produce sharply contrasting implications for the long-horizon predictive variance of returns. The model-based prior from the long-run risk model produces a predictive variance ratio in excess of one for all horizons longer than eight years, such that stocks are riskier for long-horizon investors. On the other hand, both the habit formation and prospect theory models imply that the annualized predictive variance of stocks is less than the one-year variance for all horizons considered. The variance ratios for these models initially decline sharply with horizon and reach minimums at horizons of 20 to 30 years before gradually increasing as the holding period lengthens. At a 20-year horizon, the habit formation and prospect theory models have predictive variance ratios of 0.74 and 0.60, respectively, compared with 1.13 for the long-run risk model. The variance ratio associated with the long-run risk model increases to 1.48 for a 50 -year horizon, which is very high relative to the variance ratios of 0.82 for the habit formation model and 0.62 for prospect theory investors.

Each of the subcomponents of the predictive variance contributes to the differences in modelbased inferences about long-horizon return variance. Panel B of Figure 1 shows that the long-run 
risk model produces little mean reversion, as the maximum magnitude of the effect is -0.28 . In contrast, the negative impact of mean reversion on predictive variance increases in magnitude with horizon and reaches -0.83 for habit formation and -0.71 for prospect theory. Given that expected returns are time varying in each model, uncertainty about future expected returns contributes positively to long-horizon variance. This effect more than offsets mean reversion in the long-run risk model over long horizons, such that the two opposing effects of time variation in expected returns combine to produce a net increase in predictive variance at horizons longer than 25 years. Uncertainty about future expected returns also offsets about half of the benefit of mean reversion in the habit formation model, whereas the prospect theory model implies that mean reversion is the dominant determinant of long-horizon variance. Finally, estimation risk increases with horizon for each of the three models. The long-run risk model has the highest degree of estimation risk of the three models considered, which contributes to the high variance ratios for investors with long-run risk beliefs.

We next consider the investors who estimate the VAR in Equation (1) using either uninformative priors or model-based priors. Figure 2 plots the predictive return variance ratios and three subcomponents. The thin lines represent models with uninformative priors and correspond to the VAR estimates in Panel A of Tables 1 to 3. The thick lines show results for the VARs estimated with model-based priors that are in Panel C of Tables 1 to 3.

The VARs estimated with uninformative priors produce a conclusion that stocks are safer over long horizons. Recall that the VAR associated with each model has a different $z_{t}$ state variable, such that the three models produce slightly different predictive variances. Nonetheless, the three investors with uninformative priors form quite similar conclusions about long-horizon variance. Consistent with the conventional wisdom, the predictive variance ratio is less than one at all horizons we consider. In particular, the predictive variance ratios range from 0.73 to 0.78 at a 20-year horizon and 0.79 to 0.86 over a 50-year holding period. The benefit of mean reversion, with effects of -0.72 to -0.78 at a 50 -year horizon, more than offsets the positive contributions from uncertainty about future expected returns (0.33 to 0.40$)$ and estimation risk (0.20 to 0.22$)$ to produce lower long-horizon variance. 
Finally, we consider the predictive return variances of investors who use information from both an asset pricing model and the historical data. The investors with model-based priors form different conclusions about the long-term riskiness of stocks, as shown in Panel A of Figure 2. Specifically, investors with long-run risk priors consider stocks to be as risky or even somewhat riskier over long horizons, whereas investors with priors from the habit formation and prospect theory models view stocks as being quite safe over the long run. At a 50-year horizon, for example, the longrun risk investor calculates a predictive variance ratio of 1.01, which is high compared with the corresponding figures of 0.59 for habit formation and 0.62 for prospect theory.

For investors with model-based priors based on the habit formation and prospect theory models, the information from historical data is largely consistent with their prior beliefs about mean reversion and uncertainty about future expected returns. The posterior beliefs in Panels B and C of Figure 2 thus reflect a substantial negative effect from mean reversion and a partially offsetting positive effect from uncertainty about future expected returns. Further, reducing the effect of estimation risk on long-horizon variance is one of the primary sources of potential gain from incorporating multiple sources of information. Panel D confirms that estimation risk is much lower for these investors after considering information from both the model and historical data. For both the habit formation and prospect theory models, the reduction in estimation risk relative to the uninformative prior case accounts for the majority of the difference between the predictive variance ratios with uninformative and model-based priors. After taking all of these effects into account, investors who form prior beliefs based on the habit formation or prospect theory models before considering the historical data conclude that stocks are much safer over long horizons.

In contrast to the habit formation and prospect theory investors, long-run risk investors view stocks as being slightly riskier over long holding periods. Relative to the case with uninformative priors, the effects of mean reversion and uncertainty about future expected returns in Panels B and $\mathrm{C}$ of Figure 2 are muted with model-based priors. The posterior beliefs about these components of predictive variance are relatively similar to the prior beliefs implied by the model in Figure 1. Estimation risk in Panel D is attenuated relative to the model-based prior, contributing 0.13 to the predictive variance ratio at a 50-year horizon compared with 0.39 for the long-run risk prior. 
The reduced effect of estimation risk after incorporating the data is responsible in large part for the reduction in the variance ratio relative to the model-only case.

Prior information from the long-run risk model has large economic impacts on the mean reversion and future expected return uncertainty components of predictive return variance. The magnitude of these effects reflects substantial uncertainty about return dynamics that remains after learning from historical data. To illustrate this point, Figure 3 shows posterior distributions of the effect of mean reversion on the predictive variance ratio. More specifically, the figure plots the posterior distribution of the component of return variance attributable to mean reversion from Equation (8), $\sum_{i=1}^{k-1} 2 b_{r}\left(I-B_{x}\right)^{-1}\left(I-B_{x}^{i}\right) \Sigma_{x r}$, as a proportion of $k \operatorname{Var}\left(r_{T, T+1} \mid D_{T}\right)$. The mean reversion component plotted in Panel B of Figures 1 and 2 is calculated as the posterior mean of this quantity. Panels A to $\mathrm{C}$ show results from the VARs estimated with uninformative priors, Panels D to $\mathrm{F}$ display the model-based prior distributions, and Panels G to I plot the posterior distributions for VARs estimated using model-based priors. Each panel plots posteriors corresponding to horizons of 10,20 , and 50 years.

Panels A to $\mathrm{C}$ of Figure 3 display the posterior distributions of the mean reversion component for the VARs with uninformative priors. Even after observing 141 years of historical data, the posterior distributions are quite diffuse, especially at long horizons. The posteriors indicate that a wide range of mean reversion effects are considered to be within the realm of possibility from the investor's perspective. While the overall effect of mean reversion on the predictive variance ratio depends on the mean of this posterior distribution as shown in Section 2, uncertainty about the mean reversion component is relevant as we consider the impact of introducing prior information from asset pricing models.

The implications of the model-based priors for mean reversion are shown in Panels D to F of Figure 3. The long-run risk model places relatively little weight on large negative values of mean reversion, whereas the habit formation and prospect theory models produce distributions of the mean reversion component that are visually similar to those from the data in Panels B and C. Finally, Panels G to I show posteriors from VARs with model-based priors. The posterior distributions of mean reversion are noticeably less diffuse for each of these three models compared with 
the VARs with uninformative priors. Prior information from the long-run risk model is particularly impactful on beliefs about mean reversion. Importantly, the mean reversion component depends on a nonlinear function of VAR parameters, such that modest changes in the underlying parameter values can produce economically meaningful effects. Interestingly, the posteriors for the long-run risk and prospect theory models in Panels G and I are shifted toward zero relative to both the related data-based and model-based distributions, which further illustrates the complex interactions between VAR parameters that give rise to mean reversion. Overall, substantial uncertainty about mean reversion remains after observing the historical data, and prior information from asset pricing models can have economically meaningful effects on beliefs about this aspect of returns.

\subsection{The roles of dividends and valuation changes over long horizons}

In addition to implications for long-horizon return variance, the VAR in Equation (1) models the dynamics of market dividends and valuation. In this section, we analyze the predictive variance of dividend growth as implied by VARs that consider information from a model, the historical data, or both the data and a model. We also study a decomposition of return variance into six components (both variances and covariances) that reflect the effects of dividend growth, dividend income, and changes in market valuation on uncertainty about long-horizon returns. This analysis serves two purposes. First, we can gain a better understanding of asset pricing model implications for market cash flows and valuation in comparison to the evidence in the data. Second, decomposing returns allows us to further investigate the patterns in predictive return variance shown in Section 4.2.

The contribution of the predictive variance of dividend growth to the predictive variance ratio for returns as implied by the model-based priors is shown in Panel A of Figure 4. At each horizon, the predictive dividend growth variance is scaled by one-period return variance times horizon $\left(\operatorname{Var}\left(\Delta d_{T, T+k} \mid D_{T}\right) /\left(k \operatorname{Var}\left(r_{T, T+1} \mid D_{T}\right)\right)\right)$. Panels B to D plot components of predictive dividend growth variance that measure the effects of mean reversion, uncertainty about future expected dividend growth, and estimation risk. Each of these components is scaled by $k \operatorname{Var}\left(r_{T, T+1} \mid D_{T}\right)$, such that the figure shows contributions to the predictive variance ratio of returns. Expressions for the predictive variance of dividend growth and its components as functions of VAR parameters are 
available in the Online Appendix.

Panel A of Figure 4 shows that dividend growth uncertainty contributes about half of the predictive return variance at a one-year horizon for each model. This proportion increases with horizon for all three models, but the effect of dividend growth in the long-run risk model is much more pronounced. In particular, the predictive variance of dividend growth is $57 \%$ of the magnitude of predictive variance growth at a one-year horizon in the long-run risk model, but this proportion increases to $166 \%$ at a 50-year horizon. The comparable 50-year horizon figures for the habit formation and prospect theory models are $81 \%$ and $67 \%$, respectively. The observed patterns can be traced to the assumptions of the long-run risk, habit formation, and prospect theory models about cash-flow dynamics. As previously discussed, the long-run risk model assumes that expected dividend growth is time varying, whereas the habit formation and prospect theory models assume i.i.d. dividend growth. Therefore, the VARs implied by the habit formation and prospect theory models have negligible effects from mean reversion and uncertainty about future expected dividend growth in Panels B and $\mathrm{C}$ of Figure 4. In the long-run risk model, on the other hand, time variation in expected dividend growth produces substantial uncertainty, as shown in Panel C. Estimation risk in Panel D has a positive effect on the predictive dividend growth variance for each model and largely accounts for the positive slopes in Panel A for the habit formation and prospect theory models.

The results for dividend growth are shown in Figure 5 for the VARs estimated with uninformative (thin lines) and model-based (thick lines) priors. Beginning with the VARs with uninformative priors, Panel A shows that dividend growth variance contributes about $40 \%$ to return variance at a one-year horizon, and this effect increases to reach about $100 \%$ at a 50 -year horizon. Panels B and $\mathrm{C}$ indicate that uncertainty about future expected dividend growth contributes strongly to the increase in predictive dividend growth variance with horizon, but this effect is partially offset by evidence of mean reversion in dividend growth from the historical data. The predictability of dividend growth evident in the VAR estimates in Panel A of Tables 1 to 3 contributes to both of these effects. The general patterns of dividend growth variance and its components are thus somewhat more consistent with the long-run risk model than the i.i.d. assumptions of the habit 
formation and prospect theory models, although the magnitudes of the effects are generally lower in the data compared with the long-run risk model.

Figure 5 shows that investors who update their model-based priors after observing historical data have differing views on the predictive variance of dividend growth. Long-run risk investors strengthen their belief of substantial uncertainty about future expected dividend growth and benefit from a large reduction in estimation risk. The predictive variance of dividend growth is high for such investors relative to the uninformative prior results, as the predictive dividend growth variance reaches 1.27 times the predictive return variance at a 50-year horizon. In contrast, the modelbased priors from the habit formation and prospect theory investors cause the mean reversion and uncertainty about future expected dividend growth components to be muted relative to the data. Along with large reductions in estimation risk, these effects produce relatively low predictive variances of dividend growth over long horizons.

The findings in Figures 4 and 5 that the predictive variance of dividend growth can exceed the predictive return variance for some models and horizons implies that dividend growth interacts with other components of returns. As discussed in Section 2, cumulative stock returns can be decomposed into three components that capture cumulative dividend growth, dividend income, and changes in market valuation during the holding period. Thus, the predictive variance of returns is the sum of predictive variance and covariance terms for these components, as shown in Equation (10). The VAR in Equation (1) can be used to study the dynamics of these components and the resulting implications for stock market returns.

Figure 6 presents the results from decomposing predictive return variance into six components as implied by the model-based priors. Panel A reproduces the predictive variance of returns from Figure 1 for ease of reference. The remaining six panels show the predictive variances of dividend growth (Panel B), dividend income over the holding period (Panel C), and the change in the pricedividend ratio (Panel D), as well as the effects of predictive covariances between dividend growth and dividend income (Panel E), dividend growth and the change in valuation (Panel F), and dividend income and the change in valuation (Panel G). Each effect is scaled by $k \operatorname{Var}\left(r_{T, T+1} \mid D_{T}\right)$ and the predictive covariances are multiplied by two, such that the figure shows the contributions 
of each component to the predictive return variance.

The results in Figure 6 show that the relative importance of dividend growth versus valuation effects has strong horizon effects for each model. At the one-year horizon, the long-run risk model implies that dividend growth variance in Panel $\mathrm{C}$ and the variance of valuation changes in Panel $\mathrm{E}$ each make contributions of about 0.50 to return variance. The prospect theory model and, to a lesser extent, the habit formation model also rely on a positive covariance between dividend growth and valuation changes in Panel $\mathrm{F}$ to produce short-term return variance. In both models, unexpected shocks to dividend growth in an i.i.d. economy lead to changes in effective risk aversion that magnify the shock's effect on returns. For example, the prospect theory model produces contributions to one-period return variance of 0.40 from dividend growth variance, 0.15 from valuation variance, and 0.48 from the covariance between dividend growth and valuation changes. As the horizon grows, the per-period effect of the predictive variance of valuation changes declines and the predictive variance of dividend growth dominates. The remaining components make relatively smaller contributions for each model. In particular, the predictive variance of dividend income in Panel $\mathrm{C}$ is low in economic magnitude for each model. The most notable contribution of any predictive covariance at long horizons is the negative effect of the predictive covariance between dividend growth and dividend income in Panel $\mathrm{E}$ for the long-run risk model. This negative covariance arises because realizations of high cumulative dividend growth tend to occur when the valuations are relatively high due to high expected dividend growth, which simultaneously produces relatively low dividend yields.

Figure 7 decomposes return variance for the VARs with uninformative (thin lines) and modelbased (thick lines) priors. Relative to the predictions of each model-based prior in Figure 6, the VARs estimated with uninformative priors imply much larger effects on predictive return variance from the predictive variances of dividend income and valuation changes in Panels $\mathrm{C}$ and $\mathrm{D}$. These effects arise because the data-based VARs suggest that the price-dividend ratio is more uncertain at both short and long horizons compared with the model-based prior VARs. Moving to the predictive covariances, the joint effect of dividend growth and valuation changes is large and negative at short horizons, which is contradictory to the predictions of the habit formation and prospect theory 
models. The VARs with uninformative priors also produce large negative effects from the predictive covariance between dividend growth and dividend income at long horizons in Panel E. These effects arise from evidence of a positive association between expected dividend growth and the pricedividend ratio, which in turn contributes to a negative relation between expected dividend growth and the dividend yield. Finally, substantial uncertainty about the future price-dividend ratio in the data contributes to a relatively large negative effect from the predictive covariance between dividend income and valuation changes in Panel G compared with model-based predictions.

Results from incorporating information from a model and the data are shown as thick lines in Figure 7. Relative to the model-only cases in Figure 6, these investors perceive greater uncertainty from valuation changes and dividend income in Panels $\mathrm{C}$ and $\mathrm{D}$ after observing the historical data. However, these effects are substantially attenuated relative to the cases with uninformative priors. Each of these investors also believes that the short-term covariance between dividend growth and valuation in Panel $\mathrm{F}$ has a negative effect on return variance, which runs counter to the model-based priors for the habit formation and prospect theory models. The covariance terms are generally lower in magnitude with model-based priors relative to the uninformative prior cases, with the exception of the relation between dividend growth and dividend income for the long-run risk model in Panel E.

Importantly, Figure 7 shows that the three investors who draw inferences about predictive return variance from both an asset pricing model and historical data come to different conclusions primarily because of dividend growth uncertainty. Each of the models with model-based priors produces similar implications for the effects of valuation changes and dividend income, and these effects are muted relative to the data-based approach with uninformative priors. Cumulative dividend growth is highly uncertain for investors who learn from the long-run risk model, whereas investors with habit formation and prospect theory priors believe that long-horizon dividend growth is relatively safe. As a result, stocks appear to be quite safe for habit formation and prospect theory investors, whereas long-run risk investors view stocks as somewhat riskier over the longest horizon we consider. 


\section{Conclusion}

The conventional wisdom that stocks are safer over long horizons due to mean reversion in returns (e.g., Siegel 2007) provides the basis for the common financial advice that long-term investors should overweight stocks. We find that incorporating prior information from the habit formation or prospect theory models reinforces beliefs in mean reversion and inferences that stocks are quite safe over long horizons. On the other hand, investors who form priors based on the long-run risk model conclude that stocks are as risky or even riskier for long-horizon investors. This finding that stocks could be riskier over long holding periods is in line with the recent conclusions of Pástor and Stambaugh (2012). Whereas the implications are similar, the mechanisms are quite different. Pástor and Stambaugh (2012) emphasize the role of parameter uncertainty, including uncertainty about the current value of the equity premium. Our results depend on prior beliefs motivated by economic theory, and the model-based prior from the long-run risk model has a strong impact on beliefs about mean reversion due to the remaining uncertainty about return predictability and other important aspects of returns after observing the historical data. The predictive variance of returns would likely be even higher if the two complementary frameworks were combined, and we leave this important topic for future research. 


\section{References}

Ai, H., and D. Kiku. 2013. Growth to value: Option exercise and the cross section of equity returns. Journal of Financial Economics 107:325-49.

Avramov, D. 2002. Stock return predictability and model uncertainty. Journal of Financial Economics 64:423-58.

- 2004. Stock return predictability and asset pricing models. Review of Financial Studies 17:699-738.

Avramov, D., S. Cederburg, and S. Hore. 2011. Cross-sectional asset pricing puzzles: A long-run perspective. Working Paper, Hebrew University.

Avramov, D., and R. Wermers. 2006. Investing in mutual funds when returns are predictable. Journal of Financial Economics 81:339-77.

Bansal, R., R. Dittmar, and D. Kiku. 2009. Cointegration and consumption risks in asset returns. Review of Financial Studies 22:1343-75.

Bansal, R., R. F. Dittmar, and C. T. Lundblad. 2005. Consumption, dividends, and the cross section of equity returns. Journal of Finance 60:1639-72.

Bansal, R., D. Kiku, and A. Yaron. 2012. An empirical evaluation of the long-run risks model for asset prices. Critical Finance Review 1:183-221.

Bansal, R., and A. Yaron. 2004. Risks for the long run: A potential resolution of asset pricing puzzles. Journal of Finance 59:1481-509.

Barberis, N. 2000. Investing for the long run when returns are predictable. Journal of Finance $55: 225-64$.

Barberis, N., and M. Huang. 2008. Stocks as lotteries: The implications of probability weighting for security prices. American Economic Review 98:2066-100.

Barberis, N., M. Huang, and T. Santos. 2001. Prospect theory and asset prices. Quarterly Journal of Economics 116:1-53.

Barberis, N., A. Mukherjee, and B. Wang. 2016. Prospect theory and stock returns: An empirical test. Review of Financial Studies 29:3068-107.

Beeler, J., and J. Y. Campbell. 2012. The long-run risks model and aggregate asset prices: An empirical assessment. Critical Finance Review 1:141-82.

Bidder, R., and M. E. Smith. 2015. Doubts and variability: A robust perspective on exotic consumption series. Working Paper, Federal Reserve Bank of San Francisco.

Binsbergen, J., and R. S. J. Koijen. 2010. Predictive regressions: A present-value approach. Journal of Finance 65:1439-71. 
Black, F., and R. Litterman. 1992. Global portfolio optimization. Financial Analysts Journal $48: 28-43$.

Bonomo, M., R. Garcia, N. Meddahi, and R. Tédongap. 2011. Generalized disappointment aversion, long-run volatility risk, and asset prices. Review of Financial Studies 24:82-122.

Campbell, J. Y., and J. Cochrane. 1999. Force of habit: A consumption-based explanation of aggregate stock market behavior. Journal of Political Economy 107:205-51.

Campbell, J. Y., and R. J. Shiller. 1988. The dividend-price ratio and expectations of future dividends and discount factors. Review of Financial Studies 1:195-228.

Campbell, J. Y., and S. B. Thompson. 2008. Predicting excess stock returns out of sample: Can anything beat the historical average? Review of Financial Studies 21:1509-31.

Campbell, J. Y., and L. M. Viceira. 1999. Consumption and portfolio decisions when expected returns are time varying. Quarterly Journal of Economics 114:433-95.

Cochrane, J. H. 2008. The dog that did not bark: A defense of return predictability. Review of Financial Studies 21:1533-75.

Constantinides, G. M., and A. Ghosh. 2011. Asset pricing tests with long-run risks in consumption growth. Review of Asset Pricing Studies 1:96-136.

Del Negro, M., and F. Schorfheide. 2004. Priors from general equilibrium models for VARs. International Economic Review 45:643-73.

Del Negro, M., F. Schorfheide, F. Smets, and R. Wouters. 2007. On the fit of New Keynesian models. Journal of Business and Economic Statistics 25:123-43.

Epstein, L. G., and S. E. Zin. 1989. Substitution, risk aversion, and the temporal behavior of consumption and asset returns: A theoretical framework. Econometrica 57:937-69.

Fama, E. F., and K. R. French. 1988. Dividend yields and expected stock returns. Journal of Financial Economics 22:3-25.

. 1993. Common risk factors in the returns on stocks and bonds. Journal of Financial Economics 33:3-56.

Ingram, B. F., and C. H. Whiteman. 1994. Supplanting the 'Minnesota' prior: Forecasting macroeconomic time series using real business cycle model priors. Journal of Monetary Economics 34:497-510.

Kaltenbrunner, G., and L. A. Lochstoer. 2010. Long-run risk through consumption smoothing. Review of Financial Studies 23:3190-224.

Kandel, S., and R. F. Stambaugh. 1996. On the predictability of stock returns: An asset-allocation perspective. Journal of Finance 51:385-424.

Koijen, R. S. J., and S. Van Nieuwerburgh. 2011. Predictability of returns and cash flows. Annual Review of Financial Economics 3:467-91. 
Kruttli, M. 2016. From which consumption-based asset pricing models can investors profit? Evidence from model-based priors. Working Paper, Federal Reserve Board.

Lettau, M., and S. Van Nieuwerburgh. 2008. Reconciling the return predictability evidence. Review of Financial Studies 21:1607-52.

Lintner, J. 1965. The valuation of risk assets and the selection of risky investments in stock portfolios and capital budgets. Review of Economics and Statistics 47:13-37.

Litterman, R. B. 1986. Forecasting with Bayesian vector autoregressions: Five years of experience. Journal of Business and Economic Statistics 4:25-38.

Meng, J., and X. Weng. Forthcoming. Can prospect theory explain the disposition effect? A new perspective on reference points. Management Science.

Merton, R. C. 1971. Optimum consumption and portfolio rules in a continuous-time model. Journal of Economic Theory 3:373-413.

Pástor, L., and R. F. Stambaugh. 1999. Costs of equity capital and model mispricing. Journal of Finance 54:67-121.

- 2000. Comparing asset pricing models: An investment perspective. Journal of Financial Economics 56:335-81.

- 2002a. Investing in equity mutual funds. Journal of Financial Economics 63:351-80.

. 2002b. Mutual fund performance and seemingly unrelated assets. Journal of Financial Economics 63:315-49.

. 2009. Predictive systems: Living with imperfect predictors. Journal of Finance 64:1583628.

—. 2012. Are stocks really less volatile in the long run? Journal of Finance 67:431-78.

Pettenuzzo, D., A. G. Timmermann, and R. Valkanov. 2014. Forecasting stock returns under economic constraints. Journal of Financial Economics 114:517-53.

Runkle, D. E. 1987. Vector autoregressions and reality. Journal of Business and Economic Statistics $5: 128-33$.

Shanken, J., and A. Tamayo. 2012. Payout yield, risk, and mispricing: A Bayesian analysis. Journal of Financial Economics 105:131-52.

Sharpe, W. F. 1964. Capital asset prices: A theory of market equilibrium under conditions of risk. Journal of Finance 19:425-42.

Siegel, J. J. 2007. Stocks for the long run. 4th ed. New York: McGraw-Hill.

Todd, R. M. 1984. Improving economic forecasting with Bayesian vector autoregression. Federal Reserve Bank of Minneapolis Quarterly Review 8:18-29. 
Tu, J., and G. Zhou. 2010. Incorporating economic objectives into Bayesian priors: Portfolio choice under parameter uncertainty. Journal of Financial and Quantitative Analysis 45:959-86.

Wachter, J. A. 2005. Solving models with external habit. Finance Research Letters 2:210-26.

- 2006. A consumption-based model of the term structure of interest rates. Journal of Financial Economics 79:365-99.

Wachter, J. A., and M. Warusawitharana. 2009. Predictable returns and asset allocation: Should a skeptical investor time the market? Journal of Econometrics 148:162-78.

Wang, H., J. Yan, and J. Yu. 2017. Reference-dependent preferences and the risk-return trade-off. Journal of Financial Economics 123:395-414.

Yu, J. 2012. Using long-run consumption-return correlations to test asset pricing models. Review of Economic Dynamics 15:317-35. 
Table 1

Long-run risk model VAR parameter estimates

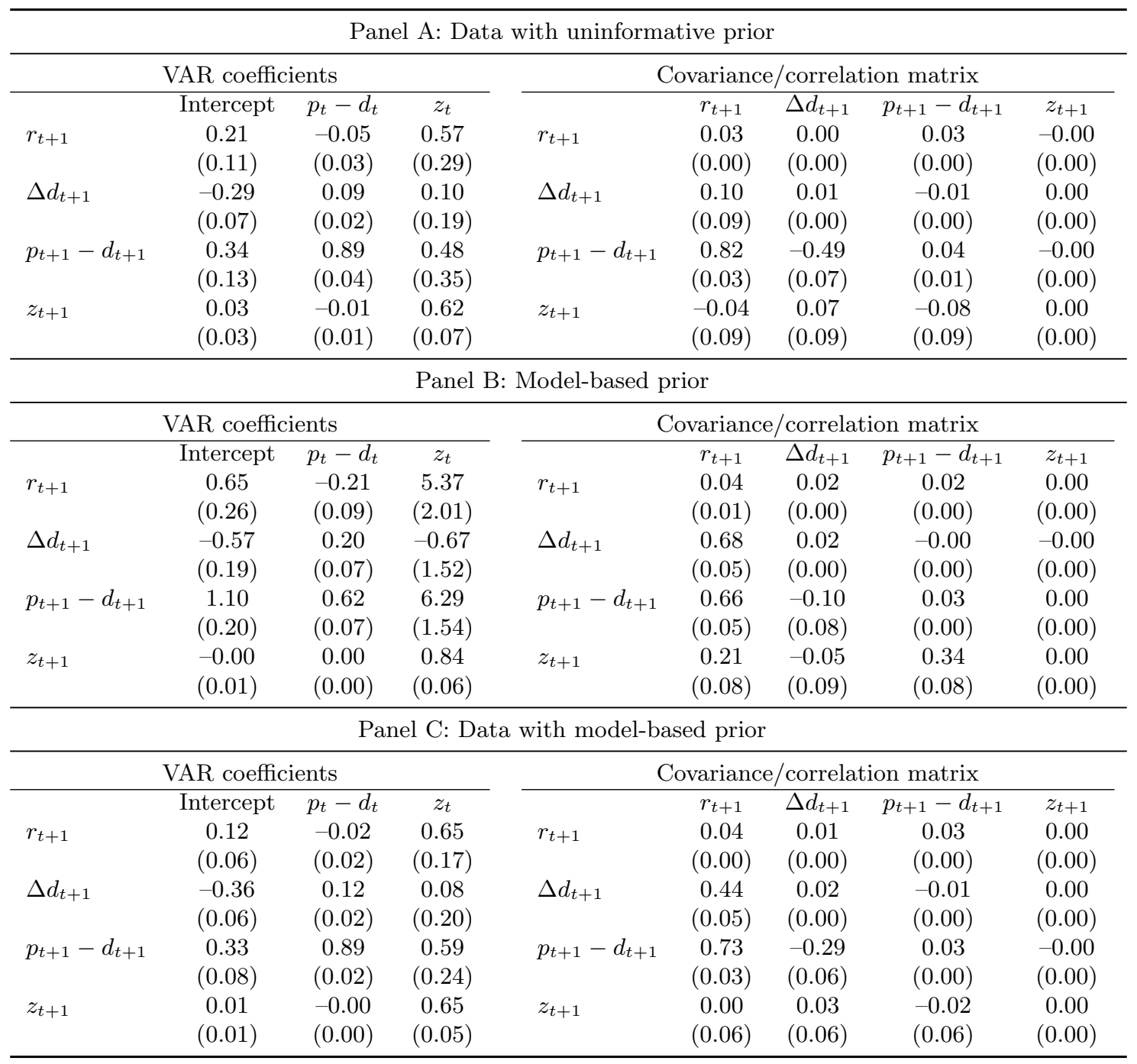

The table reports the posterior means and standard deviations of the parameters for the long-run risk VARs. The VAR specification is given in Equation (1), and the $z_{t}$ state variable is the risk-free rate as implied by the long-run risk model. Panel A shows results from a VAR with uninformative priors, Panel B reports VAR parameters for the model-based long-run risk prior, and Panel C shows the VAR posteriors using the model-based prior beliefs. The covariance/correlation matrix contains variances along the diagonal and covariances (correlations) in the upper-right (lower-left) portion of the matrix. The long-run risk model is calibrated following Bansal, Kiku, and Yaron (2012). The sample period is 1872 to 2012. 
Table 2

Habit formation model VAR parameter estimates

\begin{tabular}{|c|c|c|c|c|c|c|c|c|}
\hline \multicolumn{9}{|c|}{ Panel A: Data with uninformative prior } \\
\hline \multicolumn{4}{|c|}{ VAR coefficients } & \multicolumn{5}{|c|}{ Covariance/correlation matrix } \\
\hline & Intercept & $p_{t}-d_{t}$ & $z_{t}$ & & $r_{t+1}$ & $\Delta d_{t+1}$ & $p_{t+1}-d_{t+1}$ & $z_{t+1}$ \\
\hline$r_{t+1}$ & $\begin{array}{c}0.32 \\
(0.41)\end{array}$ & $\begin{array}{l}-0.08 \\
(0.10)\end{array}$ & $\begin{array}{l}-0.19 \\
(1.03)\end{array}$ & $r_{t+1}$ & $\begin{array}{c}0.03 \\
(0.00)\end{array}$ & $\begin{array}{c}0.00 \\
(0.00)\end{array}$ & $\begin{array}{c}0.03 \\
(0.00)\end{array}$ & $\begin{array}{l}-0.00 \\
(0.00)\end{array}$ \\
\hline$\Delta d_{t+1}$ & $\begin{array}{c}0.29 \\
(0.26)\end{array}$ & $\begin{array}{l}-0.05 \\
(0.07)\end{array}$ & $\begin{array}{l}-1.50 \\
(0.66)\end{array}$ & $\Delta d_{t+1}$ & $\begin{array}{c}0.11 \\
(0.09)\end{array}$ & $\begin{array}{c}0.01 \\
(0.00)\end{array}$ & $\begin{array}{l}-0.01 \\
(0.00)\end{array}$ & $\begin{array}{c}0.00 \\
(0.00)\end{array}$ \\
\hline$p_{t+1}-d_{t+1}$ & $\begin{array}{l}-0.14 \\
(0.48)\end{array}$ & $\begin{array}{c}1.01 \\
(0.12)\end{array}$ & $\begin{array}{c}1.36 \\
(1.21)\end{array}$ & $p_{t+1}-d_{t+1}$ & $\begin{array}{c}0.83 \\
(0.03)\end{array}$ & $\begin{array}{l}-0.47 \\
(0.07)\end{array}$ & $\begin{array}{c}0.04 \\
(0.01)\end{array}$ & $\begin{array}{l}-0.00 \\
(0.00)\end{array}$ \\
\hline$z_{t+1}$ & $\begin{array}{c}0.08 \\
(0.06)\end{array}$ & $\begin{array}{l}-0.02 \\
(0.01)\end{array}$ & $\begin{array}{c}0.68 \\
(0.14)\end{array}$ & $z_{t+1}$ & $\begin{array}{l}-0.78 \\
(0.03)\end{array}$ & $\begin{array}{c}0.43 \\
(0.07)\end{array}$ & $\begin{array}{l}-0.94 \\
(0.01)\end{array}$ & $\begin{array}{c}0.00 \\
(0.00)\end{array}$ \\
\hline \multicolumn{9}{|c|}{ Panel B: Model-based prior } \\
\hline \multicolumn{4}{|c|}{ VAR coefficients } & \multicolumn{5}{|c|}{ Covariance/correlation matrix } \\
\hline & Intercept & $p_{t}-d_{t}$ & $z_{t}$ & & $r_{t+1}$ & $\Delta d_{t+1}$ & $p_{t+1}-d_{t+1}$ & $z_{t+1}$ \\
\hline$r_{t+1}$ & $\begin{array}{l}-0.11 \\
(2.55)\end{array}$ & $\begin{array}{c}0.03 \\
(0.69)\end{array}$ & $\begin{array}{c}1.24 \\
(4.53)\end{array}$ & $r_{t+1}$ & $\begin{array}{c}0.03 \\
(0.00)\end{array}$ & $\begin{array}{c}0.02 \\
(0.00)\end{array}$ & $\begin{array}{c}0.01 \\
(0.00)\end{array}$ & $\begin{array}{l}-0.00 \\
(0.00)\end{array}$ \\
\hline$\Delta d_{t+1}$ & $\begin{array}{c}0.03 \\
(1.83)\end{array}$ & $\begin{array}{l}-0.00 \\
(0.50)\end{array}$ & $\begin{array}{l}-0.04 \\
(3.26)\end{array}$ & $\Delta d_{t+1}$ & $\begin{array}{c}0.83 \\
(0.03)\end{array}$ & $\begin{array}{c}0.01 \\
(0.00)\end{array}$ & $\begin{array}{c}0.00 \\
(0.00)\end{array}$ & $\begin{array}{l}-0.00 \\
(0.00)\end{array}$ \\
\hline$p_{t+1}-d_{t+1}$ & $\begin{array}{l}-0.31 \\
(1.50)\end{array}$ & $\begin{array}{l}1.07 \\
(0.41)\end{array}$ & $\begin{array}{c}1.34 \\
(2.67)\end{array}$ & $p_{t+1}-d_{t+1}$ & $\begin{array}{c}0.71 \\
(0.04)\end{array}$ & $\begin{array}{c}0.20 \\
(0.08)\end{array}$ & $\begin{array}{c}0.01 \\
(0.00)\end{array}$ & $\begin{array}{l}-0.00 \\
(0.00)\end{array}$ \\
\hline$z_{t+1}$ & $\begin{array}{c}0.24 \\
(0.23)\end{array}$ & $\begin{array}{l}-0.06 \\
(0.06)\end{array}$ & $\begin{array}{c}0.46 \\
(0.42)\end{array}$ & $z_{t+1}$ & $\begin{array}{l}-0.70 \\
(0.04)\end{array}$ & $\begin{array}{l}-0.20 \\
(0.08)\end{array}$ & $\begin{array}{l}-0.99 \\
(0.00)\end{array}$ & $\begin{array}{c}0.00 \\
(0.00)\end{array}$ \\
\hline \multicolumn{9}{|c|}{ Panel C: Data with model-based prior } \\
\hline \multicolumn{4}{|c|}{ VAR coefficients } & \multicolumn{5}{|c|}{ Covariance/correlation matrix } \\
\hline$r_{t+1}$ & $\begin{array}{c}\text { Intercept } \\
-0.06 \\
(0.14)\end{array}$ & $\begin{array}{c}p_{t}-d_{t} \\
0.02 \\
(0.04)\end{array}$ & $\begin{array}{c}z_{t} \\
0.95 \\
(0.33)\end{array}$ & $r_{t+1}$ & $\begin{array}{c}r_{t+1} \\
0.03 \\
(0.00)\end{array}$ & $\begin{array}{c}\Delta d_{t+1} \\
0.01 \\
(0.00)\end{array}$ & $\begin{array}{c}p_{t+1}-d_{t+1} \\
0.02 \\
(0.00)\end{array}$ & $\begin{array}{c}z_{t+1} \\
-0.00 \\
(0.00)\end{array}$ \\
\hline$\Delta d_{t+1}$ & $\begin{array}{l}-0.15 \\
(0.19)\end{array}$ & $\begin{array}{c}0.06 \\
(0.05)\end{array}$ & $\begin{array}{l}-0.17 \\
(0.44)\end{array}$ & $\Delta d_{t+1}$ & $\begin{array}{c}0.46 \\
(0.05)\end{array}$ & $\begin{array}{c}0.01 \\
(0.00)\end{array}$ & $\begin{array}{l}-0.00 \\
(0.00)\end{array}$ & $\begin{array}{c}0.00 \\
(0.00)\end{array}$ \\
\hline$p_{t+1}-d_{t+1}$ & $\begin{array}{l}-0.08 \\
(0.22)\end{array}$ & $\begin{array}{c}1.01 \\
(0.06)\end{array}$ & $\begin{array}{c}1.16 \\
(0.51)\end{array}$ & $p_{t+1}-d_{t+1}$ & $\begin{array}{c}0.75 \\
(0.03)\end{array}$ & $\begin{array}{l}-0.24 \\
(0.06)\end{array}$ & $\begin{array}{c}0.03 \\
(0.00)\end{array}$ & $\begin{array}{l}-0.00 \\
(0.00)\end{array}$ \\
\hline$z_{t+1}$ & $\begin{array}{c}0.06 \\
(0.03)\end{array}$ & $\begin{array}{l}-0.01 \\
(0.01)\end{array}$ & $\begin{array}{c}0.75 \\
(0.06)\end{array}$ & $z_{t+1}$ & $\begin{array}{l}-0.73 \\
(0.03)\end{array}$ & $\begin{array}{c}0.19 \\
(0.06)\end{array}$ & $\begin{array}{l}-0.94 \\
(0.01)\end{array}$ & $\begin{array}{c}0.00 \\
(0.00)\end{array}$ \\
\hline
\end{tabular}

The table reports the posterior means and standard deviations of the parameters for the habit formation VARs. The VAR specification is given in Equation (1), and the $z_{t}$ state variable is the fitted expected return implied by the habit formation model. Panel A shows results from a VAR with uninformative priors, Panel B reports VAR parameters for the model-based habit formation prior, and Panel $\mathrm{C}$ shows the VAR posteriors using the model-based prior beliefs. The covariance/correlation matrix contains variances along the diagonal and covariances (correlations) in the upper-right (lower-left) portion of the matrix. The habit formation model is calibrated following Campbell and Cochrane (1999). The sample period is 1872 to 2012. 
Table 3

Prospect theory model VAR parameter estimates

\begin{tabular}{|c|c|c|c|c|c|c|c|c|}
\hline \multicolumn{9}{|c|}{ Panel A: Data with uninformative prior } \\
\hline \multicolumn{4}{|c|}{ VAR coefficients } & \multicolumn{5}{|c|}{ Covariance/correlation matrix } \\
\hline & Intercept & $p_{t}-d_{t}$ & $z_{t}$ & & $r_{t+1}$ & $\Delta d_{t+1}$ & $p_{t+1}-d_{t+1}$ & $z_{t+1}$ \\
\hline$r_{t+1}$ & $\begin{array}{c}0.15 \\
(0.24)\end{array}$ & $\begin{array}{l}-0.03 \\
(0.06)\end{array}$ & $\begin{array}{c}0.33 \\
(0.71)\end{array}$ & $r_{t+1}$ & $\begin{array}{c}0.03 \\
(0.00)\end{array}$ & $\begin{array}{c}0.00 \\
(0.00)\end{array}$ & $\begin{array}{c}0.03 \\
(0.00)\end{array}$ & $\begin{array}{l}-0.00 \\
(0.00)\end{array}$ \\
\hline$\Delta d_{t+1}$ & $\begin{array}{c}0.12 \\
(0.15)\end{array}$ & $\begin{array}{l}-0.01 \\
(0.04)\end{array}$ & $\begin{array}{l}-1.34 \\
(0.45)\end{array}$ & $\Delta d_{t+1}$ & $\begin{array}{c}0.12 \\
(0.08)\end{array}$ & $\begin{array}{c}0.01 \\
(0.00)\end{array}$ & $\begin{array}{l}-0.01 \\
(0.00)\end{array}$ & $\begin{array}{c}0.00 \\
(0.00)\end{array}$ \\
\hline$p_{t+1}-d_{t+1}$ & $\begin{array}{l}-0.15 \\
(0.28)\end{array}$ & $\begin{array}{l}1.01 \\
(0.07)\end{array}$ & $\begin{array}{c}1.74 \\
(0.82)\end{array}$ & $p_{t+1}-d_{t+1}$ & $\begin{array}{c}0.83 \\
(0.03)\end{array}$ & $\begin{array}{l}-0.45 \\
(0.07)\end{array}$ & $\begin{array}{c}0.04 \\
(0.01)\end{array}$ & $\begin{array}{l}-0.00 \\
(0.00)\end{array}$ \\
\hline$z_{t+1}$ & $\begin{array}{c}0.11 \\
(0.04)\end{array}$ & $\begin{array}{l}-0.02 \\
(0.01)\end{array}$ & $\begin{array}{c}0.49 \\
(0.11)\end{array}$ & $z_{t+1}$ & $\begin{array}{l}-0.70 \\
(0.04)\end{array}$ & $\begin{array}{c}0.31 \\
(0.08)\end{array}$ & $\begin{array}{l}-0.80 \\
(0.03)\end{array}$ & $\begin{array}{c}0.00 \\
(0.00)\end{array}$ \\
\hline \multicolumn{9}{|c|}{ Panel B: Model-based prior } \\
\hline \multicolumn{4}{|c|}{ VAR coefficients } & \multicolumn{5}{|c|}{ Covariance/correlation matrix } \\
\hline$r_{t+1}$ & $\begin{array}{c}\text { Intercept } \\
-0.16 \\
(2.75)\end{array}$ & $\begin{array}{c}p_{t}-d_{t} \\
0.04 \\
(0.81)\end{array}$ & $\begin{array}{c}z_{t} \\
1.32 \\
(3.95)\end{array}$ & $r_{t+1}$ & $\begin{array}{c}r_{t+1} \\
0.04 \\
(0.00)\end{array}$ & $\begin{array}{c}\Delta d_{t+1} \\
0.02 \\
(0.00)\end{array}$ & $\begin{array}{c}p_{t+1}-d_{t+1} \\
0.01 \\
(0.00)\end{array}$ & $\begin{array}{c}z_{t+1} \\
-0.00 \\
(0.00)\end{array}$ \\
\hline$\Delta d_{t+1}$ & $\begin{array}{l}-0.03 \\
(1.74)\end{array}$ & $\begin{array}{c}0.01 \\
(0.51)\end{array}$ & $\begin{array}{c}0.09 \\
(2.50)\end{array}$ & $\Delta d_{t+1}$ & $\begin{array}{c}1.00 \\
(0.00)\end{array}$ & $\begin{array}{c}0.02 \\
(0.00)\end{array}$ & $\begin{array}{c}0.01 \\
(0.00)\end{array}$ & $\begin{array}{l}-0.00 \\
(0.00)\end{array}$ \\
\hline$p_{t+1}-d_{t+1}$ & $\begin{array}{l}-0.30 \\
(1.07)\end{array}$ & $\begin{array}{c}1.07 \\
(0.31)\end{array}$ & $\begin{array}{c}1.29 \\
(1.54)\end{array}$ & $p_{t+1}-d_{t+1}$ & $\begin{array}{c}0.99 \\
(0.00)\end{array}$ & $\begin{array}{c}0.98 \\
(0.00)\end{array}$ & $\begin{array}{c}0.01 \\
(0.00)\end{array}$ & $\begin{array}{l}-0.00 \\
(0.00)\end{array}$ \\
\hline$z_{t+1}$ & $\begin{array}{c}0.44 \\
(0.23)\end{array}$ & $\begin{array}{l}-0.12 \\
(0.07)\end{array}$ & $\begin{array}{c}0.19 \\
(0.33)\end{array}$ & $z_{t+1}$ & $\begin{array}{l}-0.95 \\
(0.01)\end{array}$ & $\begin{array}{l}-0.93 \\
(0.01)\end{array}$ & $\begin{array}{l}-0.97 \\
(0.00)\end{array}$ & $\begin{array}{c}0.00 \\
(0.00)\end{array}$ \\
\hline \multicolumn{9}{|c|}{ Panel C: Data with model-based prior } \\
\hline \multicolumn{4}{|c|}{ VAR coefficients } & \multicolumn{5}{|c|}{ Covariance/correlation matrix } \\
\hline$r_{t+1}$ & $\begin{array}{c}\text { Intercept } \\
-0.03 \\
(0.11)\end{array}$ & $\begin{array}{c}p_{t}-d_{t} \\
0.02 \\
(0.03)\end{array}$ & $\begin{array}{c}z_{t} \\
0.97 \\
(0.28)\end{array}$ & $r_{t+1}$ & $\begin{array}{c}r_{t+1} \\
0.03 \\
(0.00)\end{array}$ & $\begin{array}{c}\Delta d_{t+1} \\
0.01 \\
(0.00)\end{array}$ & $\begin{array}{c}p_{t+1}-d_{t+1} \\
0.02 \\
(0.00)\end{array}$ & $\begin{array}{c}z_{t+1} \\
-0.00 \\
(0.00)\end{array}$ \\
\hline$\Delta d_{t+1}$ & $\begin{array}{l}-0.06 \\
(0.12)\end{array}$ & $\begin{array}{c}0.04 \\
(0.03)\end{array}$ & $\begin{array}{l}-0.54 \\
(0.31)\end{array}$ & $\Delta d_{t+1}$ & $\begin{array}{c}0.60 \\
(0.04)\end{array}$ & $\begin{array}{c}0.01 \\
(0.00)\end{array}$ & $\begin{array}{l}-0.00 \\
(0.00)\end{array}$ & $\begin{array}{l}-0.00 \\
(0.00)\end{array}$ \\
\hline$p_{t+1}-d_{t+1}$ & $\begin{array}{l}-0.14 \\
(0.13)\end{array}$ & $\begin{array}{c}1.02 \\
(0.04)\end{array}$ & $\begin{array}{c}1.57 \\
(0.35)\end{array}$ & $p_{t+1}-d_{t+1}$ & $\begin{array}{c}0.77 \\
(0.02)\end{array}$ & $\begin{array}{l}-0.04 \\
(0.06)\end{array}$ & $\begin{array}{c}0.02 \\
(0.00)\end{array}$ & $\begin{array}{l}-0.00 \\
(0.00)\end{array}$ \\
\hline$z_{t+1}$ & $\begin{array}{c}0.09 \\
(0.02)\end{array}$ & $\begin{array}{l}-0.02 \\
(0.01)\end{array}$ & $\begin{array}{c}0.57 \\
(0.05)\end{array}$ & $z_{t+1}$ & $\begin{array}{l}-0.75 \\
(0.03)\end{array}$ & $\begin{array}{l}-0.16 \\
(0.06)\end{array}$ & $\begin{array}{l}-0.82 \\
(0.02)\end{array}$ & $\begin{array}{c}0.00 \\
(0.00)\end{array}$ \\
\hline
\end{tabular}

The table reports the posterior means and standard deviations of the parameters for the prospect theory VARs. The VAR specification is given in Equation (1), and the $z_{t}$ state variable is the fitted expected return implied by the prospect theory model. Panel A shows results from a VAR with uninformative priors, Panel B reports VAR parameters for the model-based prospect theory prior, and Panel $\mathrm{C}$ shows the VAR posteriors using the model-based prior beliefs. The covariance/correlation matrix contains variances along the diagonal and covariances (correlations) in the upper-right (lower-left) portion of the matrix. The prospect theory model is calibrated following Barberis, Huang, and Santos (2001). The sample period is 1872 to 2012. 

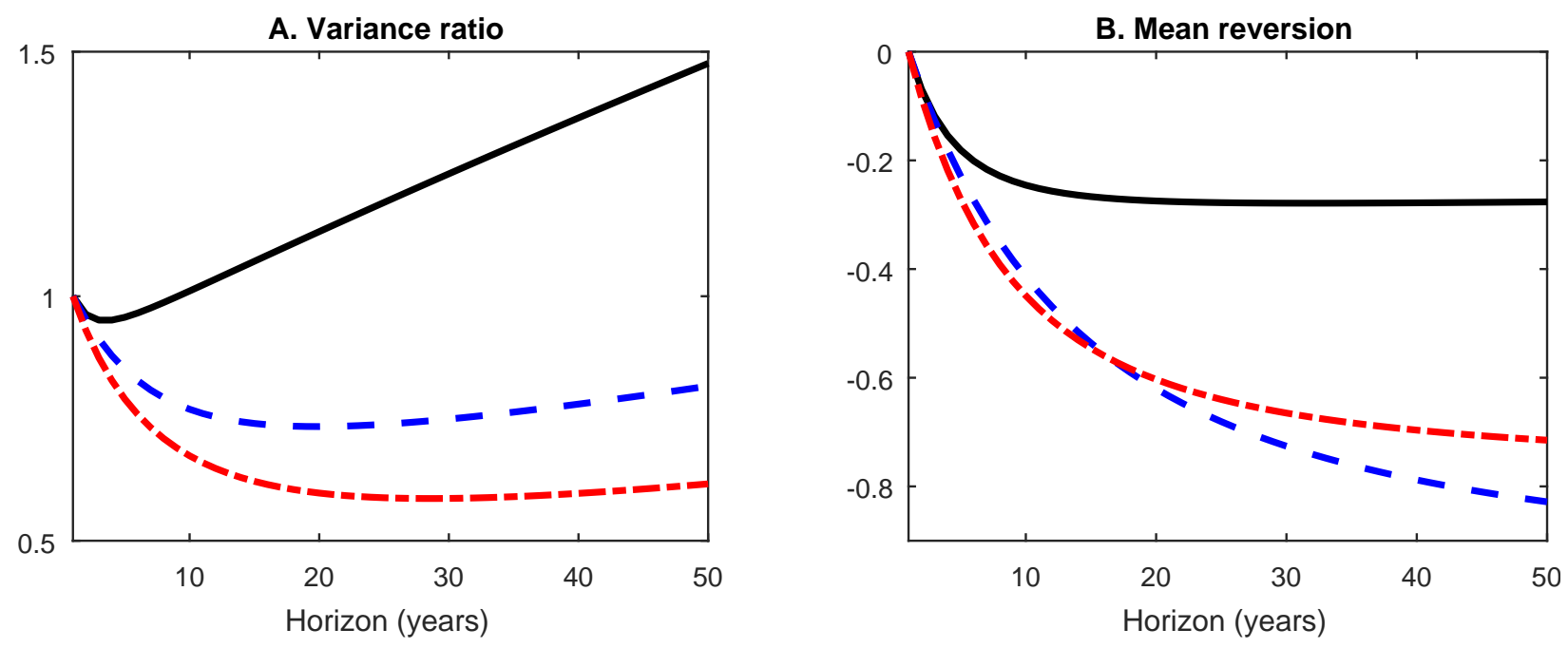

\section{Uncertainty about future expected returns}

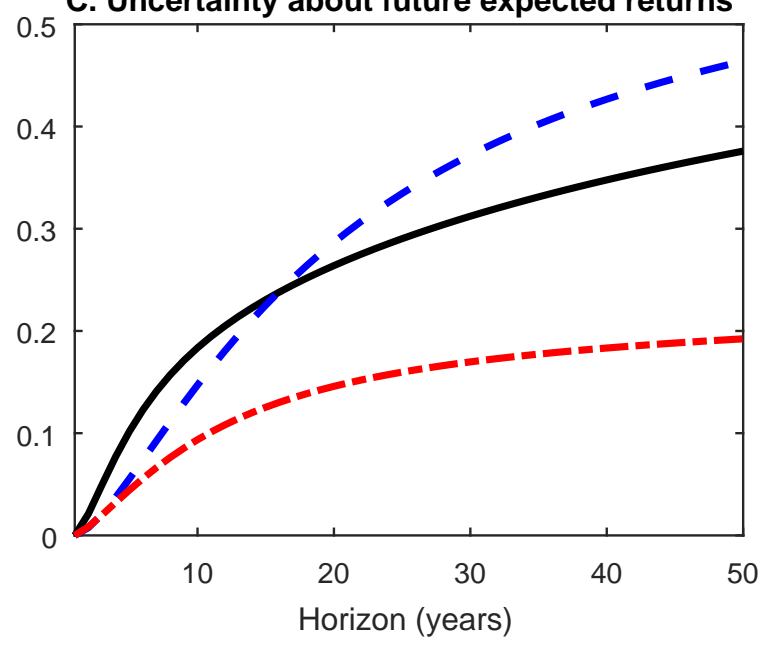

D. Estimation risk

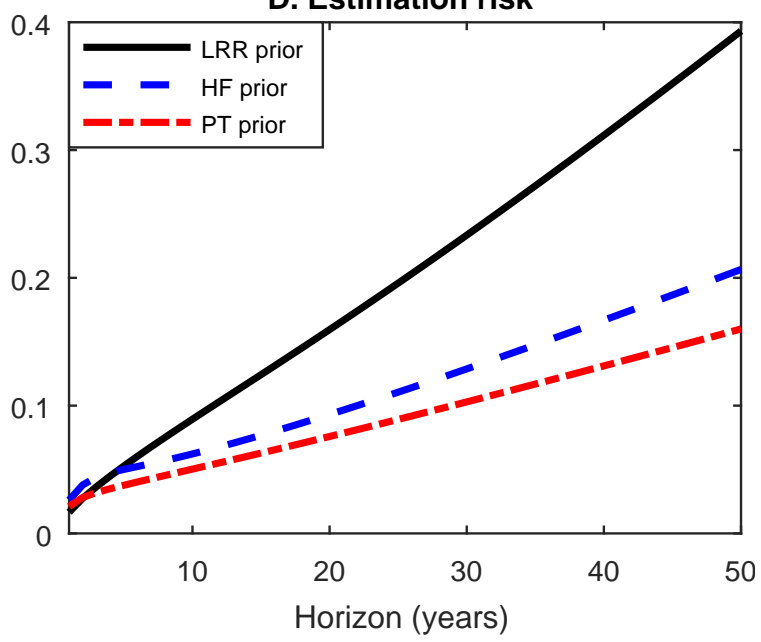

Figure 1

Predictive return variance ratio and its components by horizon implied by modelbased priors

The figure shows predictive variance ratios for returns and the components attributable to mean reversion (Panel B), uncertainty about future expected returns (Panel C), and estimation risk (Panel D) that are implied by the model-based priors from the long-run risk, habit formation, and prospect theory models. Parameter estimates for the model-based prior VARs are shown in Panel B of Tables 1 to 3 . 

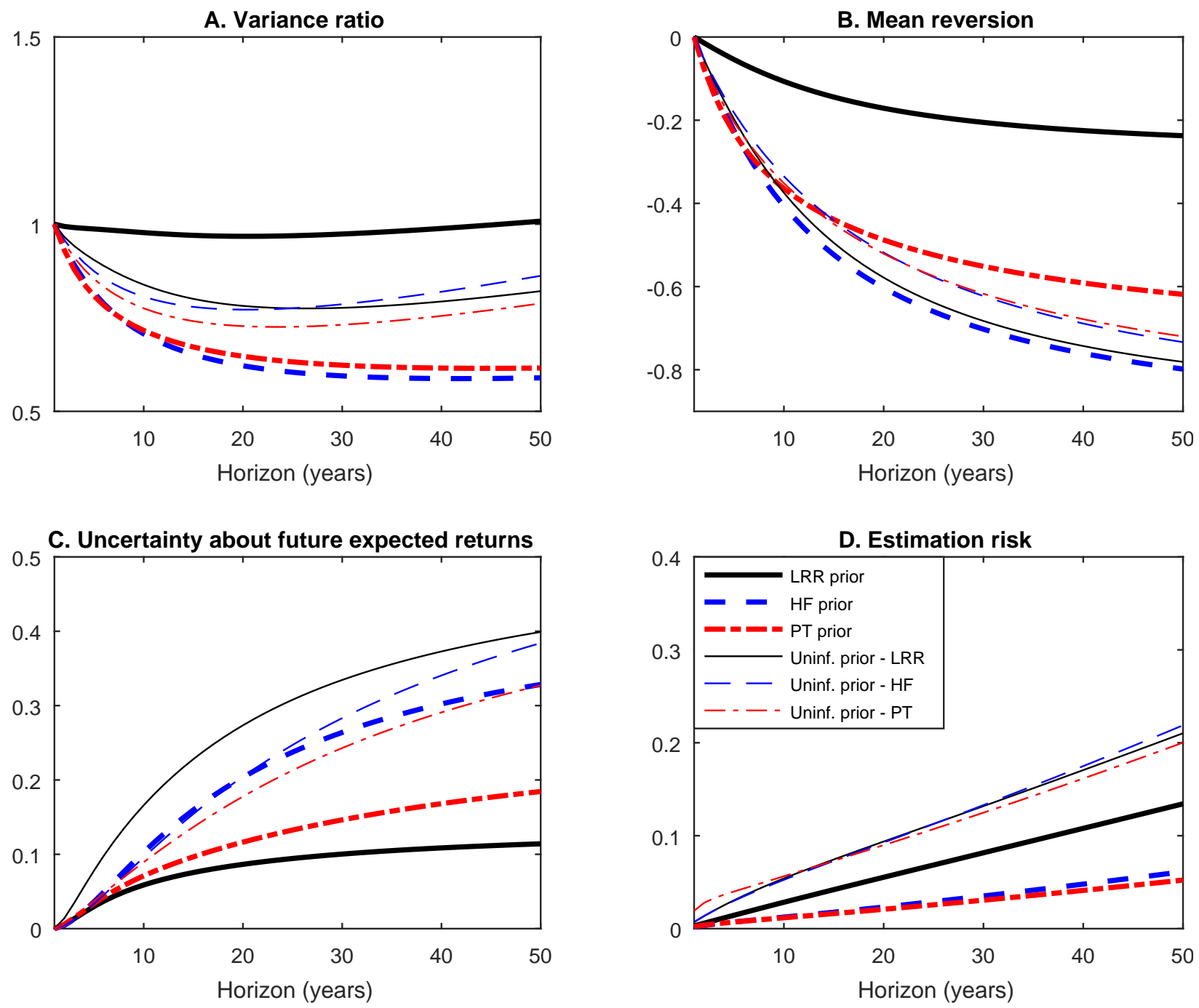

Figure 2

Predictive return variance ratio and its components by horizon using uninformative and model-based priors

The figure shows predictive variance ratios for returns and the components attributable to mean reversion, uncertainty about future expected returns, and estimation risk. The thin lines correspond to the VARs estimated using uninformative priors from Panel A of Tables 1 to 3, and the thick lines are based on VARs from Panel $\mathrm{C}$ of Tables 1 to 3 that are estimated with model-based priors implied by the long-run risk, habit formation, and prospect theory models. The sample period is 1872 to 2012. 

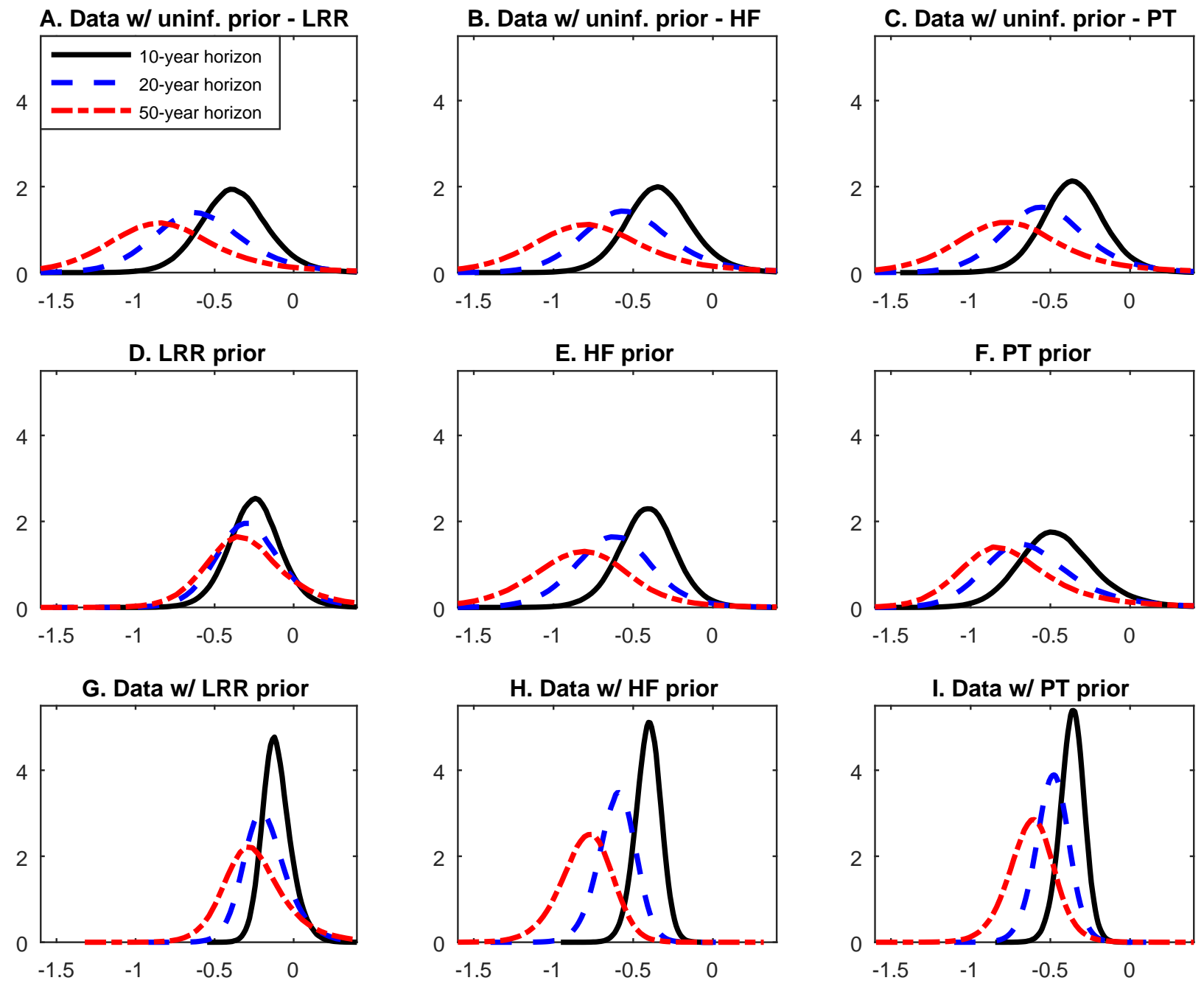

Figure 3

Posterior distributions of mean reversion component by horizon using uninformative and model-based priors

The figure shows posterior distributions of the mean reversion component of the predictive variance ratio for returns at horizons of 10,20, and 50 years. The average of the posterior draws of mean reversion is the component of the predictive variance ratio shown in Panel B of Figures 1 and 2. Panels A to $\mathrm{C}$ correspond to the VARs estimated using uninformative priors from Panel A of Tables 1 to 3. Panels D to F are from the model-based priors implied by the long-run risk, habit formation, and prospect theory models in Panel B of Tables 1 to 3. Panels G to I are based on VARs from Panel $\mathrm{C}$ of Tables 1 to 3 that are estimated with model-based priors. The sample period is 1872 to 2012. 

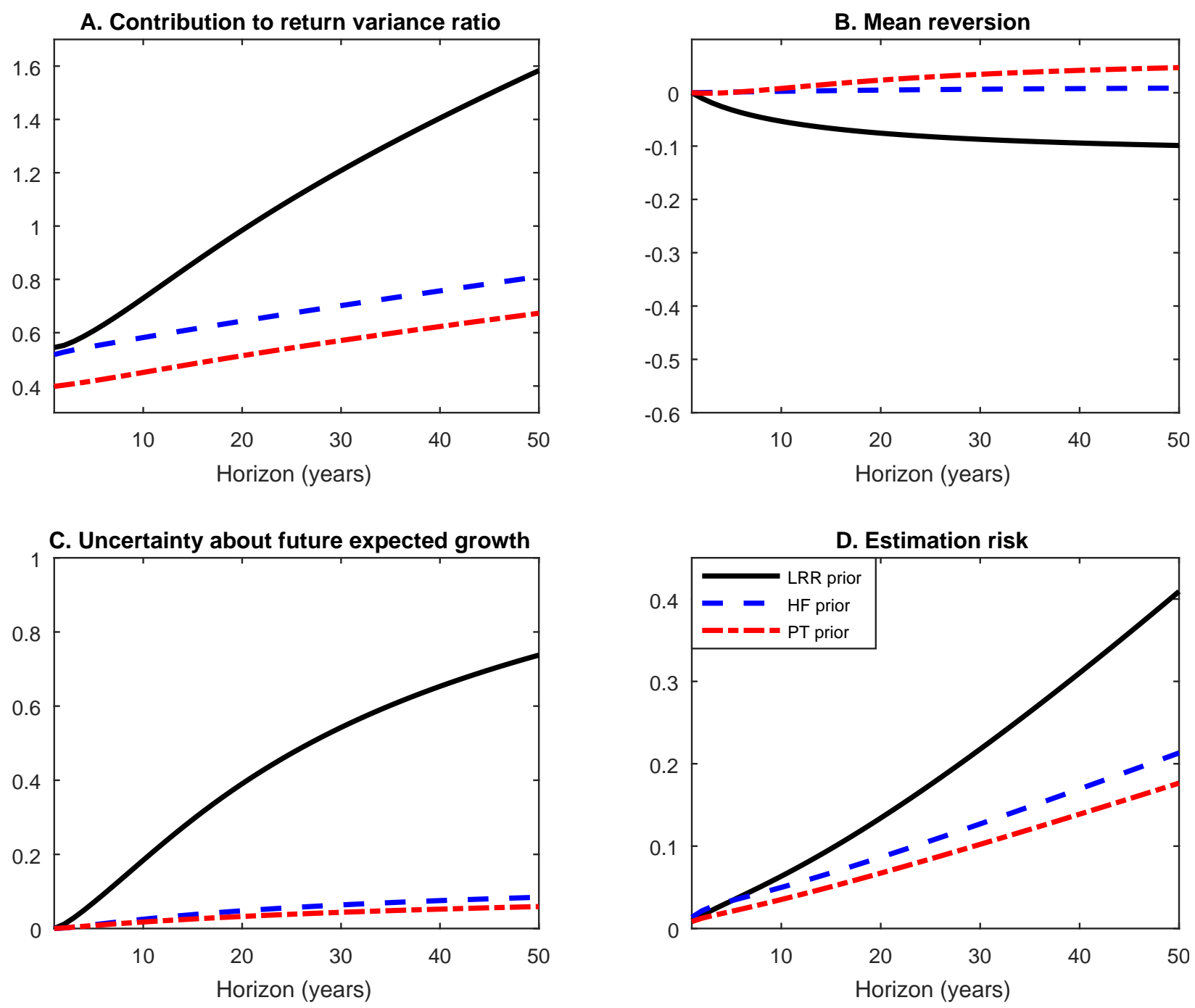

Figure 4

Contribution to return variance ratio by dividend growth implied by the model-based priors

The figure shows contributions of cumulative dividend growth to the predictive variance ratio for returns as implied by the model-based priors from the long-run risk, habit formation, and prospect theory models. Panel A plots $\operatorname{Var}\left(\Delta d_{T, T+k} \mid D_{T}\right) /\left(k \operatorname{Var}\left(r_{T, T+1} \mid D_{T}\right)\right)$ by horizon for each modelbased prior. Panels B to D show the mean reversion, uncertainty about future expected dividend growth, and estimation risk components of the predictive variance of dividend growth scaled by $k \operatorname{Var}\left(r_{T, T+1} \mid D_{T}\right)$. Parameter estimates for the model-based prior VARs are shown in Panel B of Tables 1 to 3 . 

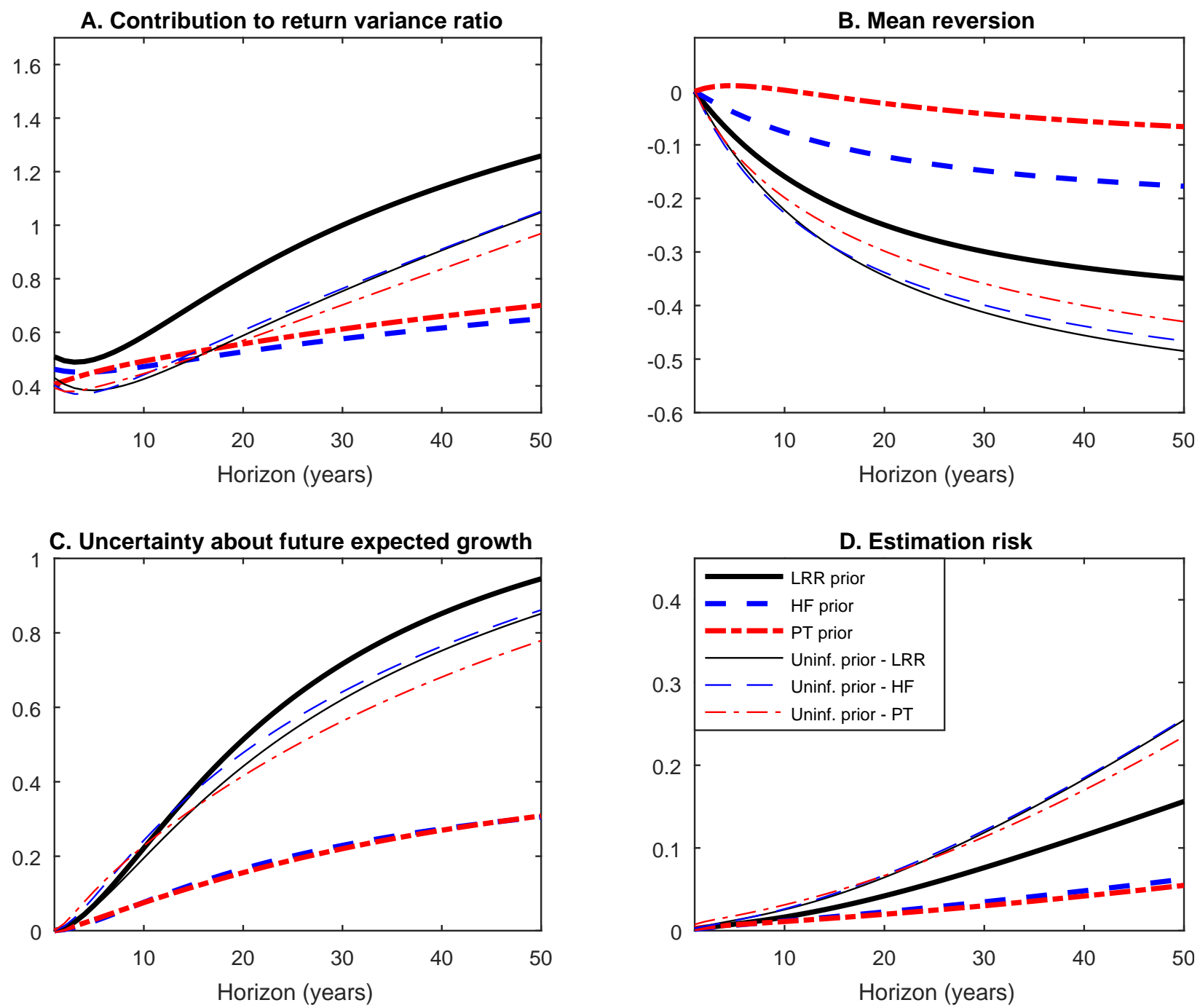

Figure 5

Contribution to return variance ratio by dividend growth using uninformative and model-based priors

The figure shows contributions of cumulative dividend growth to the predictive variance ratio for returns. Panel A plots $\operatorname{Var}\left(\Delta d_{T, T+k} \mid D_{T}\right) /\left(k \operatorname{Var}\left(r_{T, T+1} \mid D_{T}\right)\right)$ by horizon for each VAR. Panels B to $\mathrm{D}$ show the mean reversion, uncertainty about future expected dividend growth, and estimation risk components of the predictive variance of dividend growth scaled by $k \operatorname{Var}\left(r_{T, T+1} \mid D_{T}\right)$. The thin lines correspond to the VARs estimated using uninformative priors from Panel A of Tables 1 to 3 , and the thick lines are based on VARs from Panel $\mathrm{C}$ of Tables 1 to 3 that are estimated with model-based priors implied by the long-run risk, habit formation, and prospect theory models. The sample period is 1872 to 2012 . 

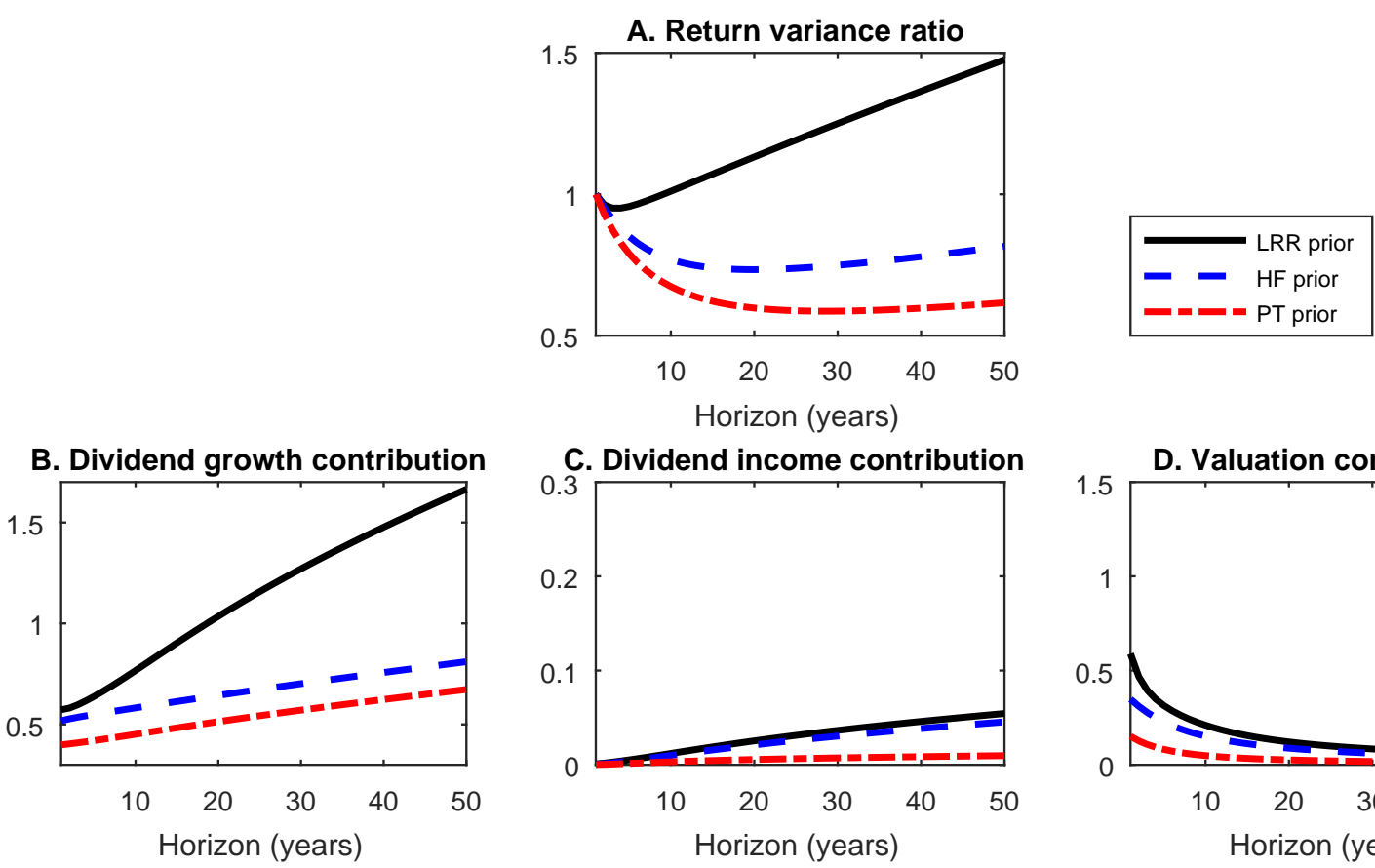

C. Dividend income contribution

D. Valuation contribution
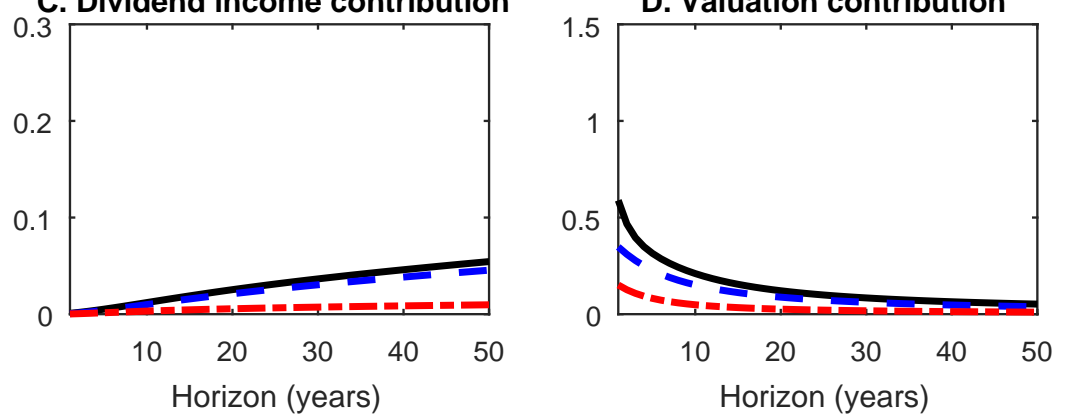

E. Dividend growth/Dividend income
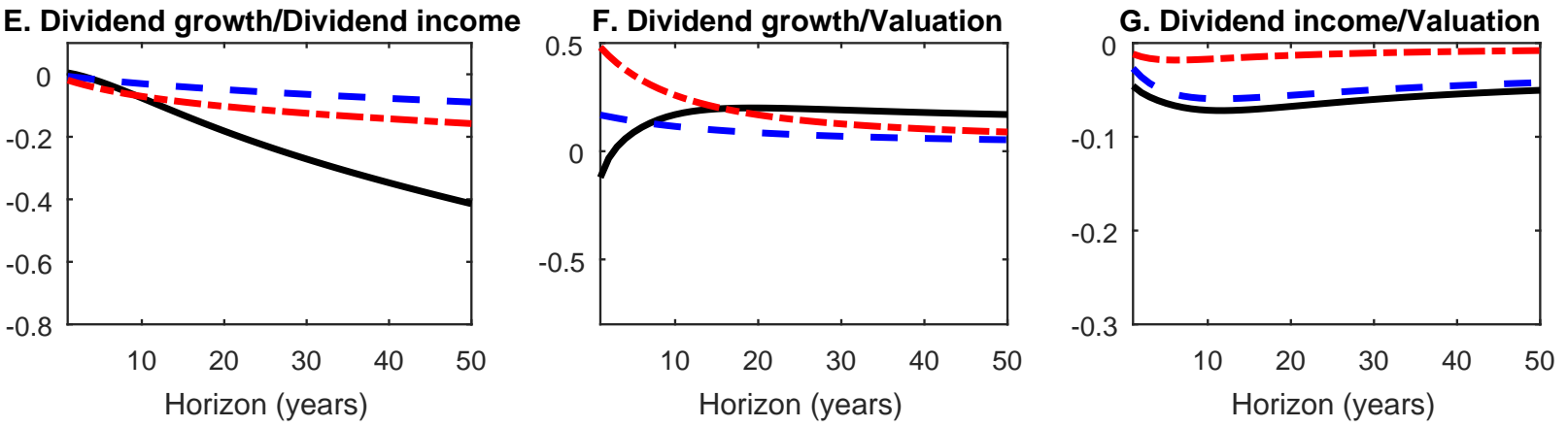

Figure 6

Decomposition of return variance ratio implied by the model-based priors

The figure shows a decomposition of the predictive variance ratio for returns into the variances and covariances associated with dividend growth, dividend income, and market valuation as implied by the model-based priors from the long-run risk, habit formation, and prospect theory models. Panel A plots the predictive return variance ratios from Panel A of Figure 1 for ease of reference. Panels $\mathrm{B}$ to $\mathrm{D}$ show the contributions to the predictive return variance ratio from the predictive variances of cumulative dividend growth, dividend income over the holding period, and changes in market valuation. Panels $\mathrm{E}$ to $\mathrm{G}$ display the effects of the predictive covariances between the dividend growth, dividend income, and valuation components on the predictive return variance ratio. Parameter estimates for the model-based prior VARs are shown in Panel B of Tables 1 to 3. 

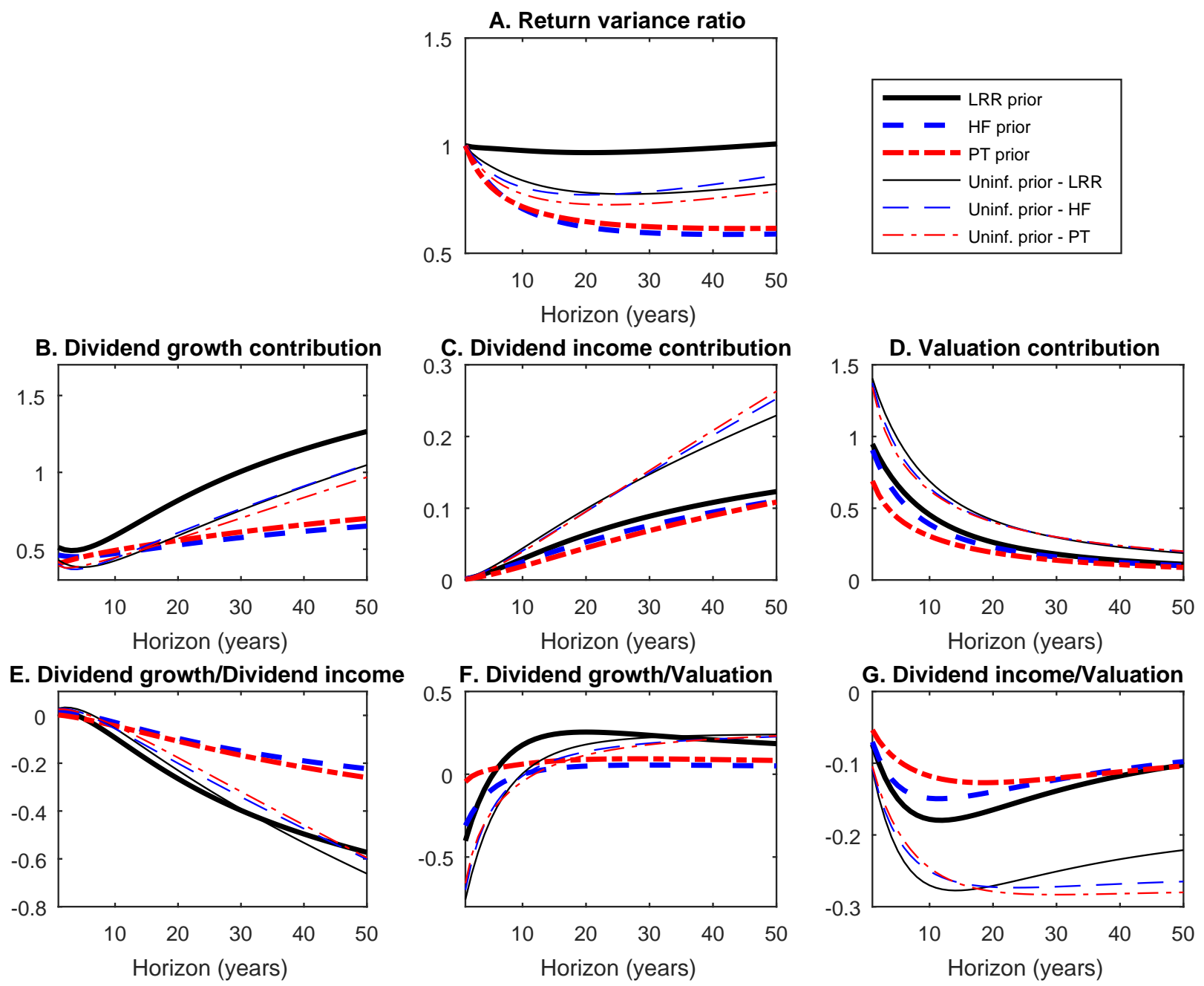

\section{Figure 7}

Decomposition of return variance ratio using uninformative and model-based priors The figure shows a decomposition of the predictive variance ratio for returns into the variances and covariances associated with dividend growth, dividend income, and market valuation. Panel A plots the predictive return variance ratios from Panel A of Figure 2 for ease of reference. Panels $\mathrm{B}$ to $\mathrm{D}$ show the contributions to the predictive return variance ratio from the predictive variances of cumulative dividend growth, dividend income over the holding period, and changes in market valuation. Panels $\mathrm{E}$ to $\mathrm{G}$ display the effects of the predictive covariances between the dividend growth, dividend income, and valuation components on the predictive return variance ratio. The thin lines correspond to the VARs estimated using uninformative priors from Panel A of Tables 1 to 3 , and the thick lines are based on VARs from Panel $\mathrm{C}$ of Tables 1 to 3 that are estimated with model-based priors implied by the long-run risk, habit formation, and prospect theory models. The sample period is 1872 to 2012 . 


\section{Online Appendix to "Are Stocks Riskier over the Long Run? Taking Cues from Economic Theory"}

Doron Avramov, Scott Cederburg, and Katarína Lučivjanská

\section{A Predictive Vector Autoregression Framework}

We adopt a predictive VAR framework,

$$
\left[\begin{array}{c}
r_{t+1} \\
\Delta d_{t+1} \\
p_{t+1}-d_{t+1} \\
z_{t+1}
\end{array}\right]=a+B\left[\begin{array}{c}
p_{t}-d_{t} \\
z_{t}
\end{array}\right]+\epsilon_{t+1}, \quad \epsilon_{t+1} \sim N(0, \Sigma)
$$

in which log stock market returns $\left(r_{t+1}\right)$ and log dividend growth $\left(\Delta d_{t+1}\right)$ are forecasted using the log price-dividend ratio $\left(p_{t}-d_{t}\right)$ and an additional predictive state variable $\left(z_{t}\right)$. In our implementation, the state variable $z_{t}$ differs across asset pricing models based on model predictions. In particular, the long-run risk model implies that the expected log stock market return and expected $\log$ dividend growth rate are linear in the price-dividend ratio and risk-free rate state variables (Constantinides and Ghosh 2011). We thus specify $z_{t}=r_{f, t}$ for this model. In both the habit formation and prospect theory models, variation in expected returns is driven by a single state variable that also produces all variation in the price-dividend ratio, such that expected return is a function of the price-dividend ratio. To capture nonlinearities in the relation between expected return and the price-dividend ratio, we include $z_{t}=f\left(p_{t}-d_{t}\right)$ as the additional state variable and estimate a nonlinear function by fitting data generated from the asset pricing model. More information about estimating $f\left(p_{t}-d_{t}\right)$ for the habit formation and prospect theory models is provided later in this appendix.

Recent studies in the return predictability literature by Cochrane (2008), Lettau and Van Nieuwerburgh (2008), Binsbergen and Koijen (2010), and Koijen and Van Nieuwerburgh (2011) jointly consider the predictability of returns and dividend growth implied by present-value rela- 
tions. Campbell and Shiller (1988) show that a log-linear approximation of the return equation produces

$$
r_{t+1}=\rho\left(p_{t+1}-d_{t+1}\right)-\left(p_{t}-d_{t}\right)+\Delta d_{t+1}+q
$$

in which $\rho=1 /(1+\exp (\overline{d-p}))$ and $q=-\log \rho-(1-\rho) \log (1 / \rho-1)$. Note that we calculate returns in our paper following Equation (A.2), such that Equation (A.2) holds exactly in our data. ${ }^{1}$ Plugging the specifications for $r_{t+1}, \Delta d_{t+1}$, and $\left(p_{t+1}-d_{t+1}\right)$ implied by the VAR into this equation gives four restrictions. Denote the intercept elements corresponding to $r_{t+1}, \Delta d_{t+1}$, and $p_{t+1}-d_{t+1}$ as $a_{r}, a_{d}$, and $a_{p d}$, respectively. Further define the coefficients of $r_{t+1}, \Delta d_{t+1}$, and $p_{t+1}-d_{t+1}$ on the $p_{t}-d_{t}\left(z_{t}\right)$ state variable as $b_{r, p d}, b_{d, p d}$, and $b_{p d, p d}\left(b_{r, z}, b_{d, z}\right.$, and $\left.b_{p d, z}\right)$, and the corresponding error term elements as $\epsilon_{r, t+1}, \epsilon_{d, t+1}$, and $\epsilon_{p d, t+1}$. Then Equation (A.2) and the VAR in Equation (A.1) imply

$$
\begin{aligned}
a_{r} & =\rho a_{p d}+a_{d}+q, \\
b_{r, p d} & =\rho b_{p d, p d}-1+b_{d, p d}, \\
b_{r, z} & =\rho b_{p d, z}+b_{d, z}, \\
\epsilon_{r, t+1} & =\rho \epsilon_{p d, t+1}+\epsilon_{d, t+1} .
\end{aligned}
$$

An implication of these relations is that the VAR in Equation (A.1) must be estimated with observation equations for only two of the $r_{t+1}, \Delta d_{t+1}$, and $p_{t+1}-d_{t+1}$ variables to ensure that the covariance matrix $\Sigma$ is nonsingular. The coefficient estimates and covariance matrix elements related to the omitted variable can then be directly calculated using Equations (A.3) to (A.6). We thus proceed to describe the estimation of a VAR that removes $\Delta d_{t+1}$ from the VAR specification during the estimation stage,

$$
\left[\begin{array}{c}
r_{t+1} \\
p_{t+1}-d_{t+1} \\
z_{t+1}
\end{array}\right]=C^{\prime}\left[\begin{array}{c}
1 \\
p_{t}-d_{t} \\
z_{t}
\end{array}\right]+\epsilon_{t+1}, \quad \epsilon_{t+1} \sim N(0, \tilde{\Sigma})
$$

\footnotetext{
${ }^{1}$ The correlation between the raw log returns and the log returns calculated using Equation (A.2) exceeds 0.99 in both the historical data and the model-based data from each model.
} 
in which

$$
C \equiv\left[\begin{array}{ccc}
a_{r} & a_{p d} & a_{z} \\
b_{r, p d} & b_{p d, p d} & b_{z, p d} \\
b_{r, z} & b_{p d, z} & b_{z, z}
\end{array}\right]
$$

The resulting estimates would be equivalent if we removed either returns or the price-dividend ratio from the VAR for estimation purposes and calculate the parameters using Equations (A.3) to (A.6).

To estimate the predictive VAR in Equation (A.7) for each asset pricing model, we produce population moments conditional on the set of parameters $\Theta$ in the individual asset pricing model:

$$
\begin{aligned}
\Gamma_{y y}^{*}(\Theta)=\mathrm{E}_{\Theta}\left[\begin{array}{ccc}
r_{t+1}^{2} & r_{t+1}\left(p_{t+1}-d_{t+1}\right) & r_{t+1} z_{t+1} \\
\left(p_{t+1}-d_{t+1}\right) r_{t+1} & \left(p_{t+1}-d_{t+1}\right)^{2} & \left(p_{t+1}-d_{t+1}\right) z_{t+1} \\
z_{t+1} r_{t+1} & z_{t+1}\left(p_{t+1}-d_{t+1}\right) & z_{t+1}^{2}
\end{array}\right], \\
\Gamma_{x y}^{*}(\Theta)=\mathrm{E}_{\Theta}\left[\begin{array}{ccc}
r_{t+1} & \left(p_{t+1}-d_{t+1}\right) & z_{t+1} \\
\left(p_{t}-d_{t}\right) r_{t+1} & \left(p_{t}-d_{t}\right)\left(p_{t+1}-d_{t+1}\right) & \left(p_{t}-d_{t}\right) z_{t+1} \\
z_{t} r_{t+1} & z_{t}\left(p_{t+1}-d_{t+1}\right) & z_{t} z_{t+1}
\end{array}\right], \\
\Gamma_{x x}^{*}(\Theta)=\mathrm{E}_{\Theta}\left[\begin{array}{ccc}
1 & \left(p_{t}-d_{t}\right) & z_{t} \\
\left(p_{t}-d_{t}\right) & \left(p_{t}-d_{t}\right)^{2} & \left(p_{t}-d_{t}\right) z_{t} \\
z_{t} & z_{t}\left(p_{t}-d_{t}\right) & z_{t}^{2}
\end{array}\right],
\end{aligned}
$$

in which $\mathrm{E}_{\Theta}$ denotes an expectation conditional on $\Theta$. We simulate 10 time series of 10,000 years of annual data and calculate averages of the moments across the 10 iterations to estimate the population moments.

We first study the prior beliefs of Bayesian investors who form their prior based on an asset pricing model. The model-based prior distributions (conditional on the set of asset pricing model parameters $\Theta$ ) for the parameters of the predictive VAR in Equation (A.7) are given by

$$
\begin{aligned}
\tilde{\Sigma} \mid \Theta & \sim I W\left(\lambda T \Sigma^{*}(\Theta), \lambda T-3\right) \\
C \mid \tilde{\Sigma}, \Theta & \sim N\left(C^{*}(\Theta), \tilde{\Sigma} \otimes\left(\lambda T \Gamma_{x x}^{*}(\Theta)\right)^{-1}\right),
\end{aligned}
$$


in which

$$
C^{*}(\Theta)=\Gamma_{x x}^{*-1}(\Theta) \Gamma_{x y}^{*}(\Theta)
$$

and

$$
\Sigma^{*}(\Theta)=\Gamma_{y y}^{*}(\Theta)-\Gamma_{x y}^{*^{\prime}}(\Theta) \Gamma_{x x}^{*-1}(\Theta) \Gamma_{x y}^{*}(\Theta)
$$

The quantity $\lambda T$ controls the level of potential model misspecification considered by the investor. Intuitively, $\lambda T$ corresponds to the size of a pseudosample of data from the asset pricing model used to inform the investor about the VAR parameters. We set $\lambda=1$ such that the size of the model-based pseudosample is equal to the empirical sample size of the historical data.

Second, we investigate investors who consider both an asset pricing model and historical data. These investors form a prior for the VAR parameters based on the implications of an asset pricing model. The model-based prior can be expressed as

$$
\begin{aligned}
p\left(Y^{*}(\Theta) \mid C, \tilde{\Sigma}\right) & \propto|\tilde{\Sigma}|^{-\lambda T / 2} \exp \left(-\frac{1}{2} \operatorname{tr}\left[\lambda T \tilde { \Sigma } ^ { - 1 } \left(\Gamma_{y y}^{*}(\Theta)\right.\right.\right. \\
& \left.\left.\left.-C^{\prime} \Gamma_{x y}^{*}(\Theta)-\Gamma_{x y}^{*^{\prime}}(\Theta) C+C^{\prime} \Gamma_{x x}^{*}(\Theta) C\right)\right]\right)
\end{aligned}
$$

in which the parameter $\lambda$ again allows for potential model misspecification and reflects the strength of the prior. The posterior distribution reflects information from both the observed data and the pseudosample implied by the economic model (conditional on the set of parameters $\Theta$ in the asset pricing model). Define $Y$ as a $T \times 3$ matrix with the vectors $y_{t+1}=\left(r_{t+1}, p_{t+1}-d_{t+1}, z_{t+1}\right)$ as rows and $\mathrm{X}$ as a $T \times 3$ matrix with the vectors $x_{t}=\left(1, p_{t}-d_{t}, z_{t}\right)$ as rows. The posterior distribution of the VAR parameters is given by

$$
\begin{aligned}
\tilde{\Sigma} \mid \Theta, D_{T} & \sim I W((\lambda+1) T \hat{\Sigma}(\Theta),(\lambda+1) T-3), \\
C \mid \tilde{\Sigma}, \Theta, D_{T} & \sim N\left(\hat{C}(\Theta), \tilde{\Sigma} \otimes\left(\lambda T \Gamma_{x x}^{*}(\Theta)+X^{\prime} X\right)^{-1}\right),
\end{aligned}
$$


in which

$$
\begin{aligned}
\hat{C}(\Theta) & =\left(\lambda T \Gamma_{x x}^{*}(\Theta)+X^{\prime} X\right)^{-1}\left(\lambda T \Gamma_{x y}^{*}(\Theta)+X^{\prime} Y\right), \\
\hat{\Sigma}(\Theta) & =\frac{1}{(\lambda+1) T}\left[\left(\lambda T \Gamma_{y y}^{*}(\Theta)+Y^{\prime} Y\right)\right. \\
& \left.-\left(\lambda T \Gamma_{x y}^{*^{\prime}}(\Theta)+Y^{\prime} X\right)\left(\lambda T \Gamma_{x x}^{*}(\Theta)+X^{\prime} X\right)^{-1}\left(\lambda T \Gamma_{x y}^{*}(\Theta)+X^{\prime} Y\right)\right],
\end{aligned}
$$

and $D_{T}$ denotes available sample information up to time $T$.

Finally, we restrict the draws to allow only positive equity premiums. Each VAR models the expected stock market return, such that we need to adjust for the risk-free rate to constrain the expected excess return. The VAR for the long-run risk model includes the risk-free rate as the state variable $z_{t}$, such that the posterior distribution with constraints in this case is given by

$$
\begin{aligned}
\tilde{\Sigma} \mid \Theta, D_{T} & \sim I W((\lambda+1) T \hat{\Sigma}(\Theta),(\lambda+1) T-3), \\
C \mid \tilde{\Sigma}, \Theta, D_{T} & \sim N\left(\hat{C}(\Theta), \tilde{\Sigma} \otimes\left(\lambda T \Gamma_{x x}^{*}(\Theta)+X^{\prime} X\right)^{-1}\right) \times\left(a_{r}, b_{r, p d}, b_{r, z}, a_{z}, b_{z, p d}, b_{z, z}\right) \in A_{T},
\end{aligned}
$$

in which $A_{T}=\left\{\left(a_{r}+b_{r, p d}\left(p_{\tau}-d_{\tau}\right)+b_{r, z} z_{\tau}\right)-\left(a_{z}+b_{z, p d}\left(p_{\tau}-d_{\tau}\right)+b_{z, z} z_{\tau}\right) \geq 0, \tau=1, \ldots, T\right\}$. We accept the draw $(C, \tilde{\Sigma})$ only if $\left(a_{r}, b_{r, p d}, b_{r, z}, a_{z}, b_{z, p d}, b_{z, z}\right)$ is from the set $A_{T}$. This approach drops the parameters that imply a negative equity premium for at least one time $\tau$ and keep the parameters that generate a positive equity premium over the full sample period. The VARs for the habit formation and prospect theory models do not model the risk-free rate, and the models imply constant risk-free rates. For these cases, we run a separate Bayesian predictive regression with uninformative priors for the real risk-free rate,

$$
r_{f, t+1}=a_{r f}+b_{r f, p d}\left(p_{t}-d_{t}\right)+b_{r f, r f} r_{f, t}+\epsilon_{r f, t+1}
$$

and only accept posterior draws in which $\left(a_{r}, b_{r, p d}, b_{r, z}, a_{r f}, b_{r f, p d}, b_{r f, r f}\right)$ is in the set $A_{T}=\left\{\left(a_{r}+\right.\right.$ $\left.\left.b_{r, p d}\left(p_{\tau}-d_{\tau}\right)+b_{r, z} z_{\tau}\right)-\left(a_{r f}+b_{r f, p d}\left(p_{\tau}-d_{\tau}\right)+b_{r f, r f} r_{f, \tau}\right) \geq 0, \tau=1, \ldots, T\right\}$. We also investigate a specification that uses the model-implied risk-free rate for the nonnegativity constraint in Online Appendix C. Inferences are similar to the base case.

Given the draws of $C$, the parameters $a$ and $B$ of the VAR in Equation (A.1) can be calculated 
using the definition in Equation (A.8) and the restrictions in Equations (A.3) to (A.5). The $\Sigma$ parameter is constructed using the $\tilde{\Sigma}$ draw along with the implications of Equation (A.6) that

$$
\begin{aligned}
\operatorname{Var}\left(\epsilon_{d, t+1}\right) & =\operatorname{Var}\left(\epsilon_{r, t+1}\right)+\rho^{2} \operatorname{Var}\left(\epsilon_{p d, t+1}\right)-2 \rho \operatorname{Cov}\left(\epsilon_{r, t+1}, \epsilon_{p d, t+1}\right), \\
\operatorname{Cov}\left(\epsilon_{d, t+1}, \epsilon_{r, t+1}\right) & =\operatorname{Var}\left(\epsilon_{r, t+1}\right)-\rho \operatorname{Cov}\left(\epsilon_{r, t+1}, \epsilon_{p d, t+1}\right), \\
\operatorname{Cov}\left(\epsilon_{d, t+1}, \epsilon_{p d, t+1}\right) & =\operatorname{Cov}\left(\epsilon_{r, t+1}, \epsilon_{p d, t+1}\right)-\rho \operatorname{Var}\left(\epsilon_{p d, t+1}\right), \\
\operatorname{Cov}\left(\epsilon_{d, t+1}, \epsilon_{z, t+1}\right) & =\operatorname{Cov}\left(\epsilon_{r, t+1}, \epsilon_{z, t+1}\right)-\rho \operatorname{Cov}\left(\epsilon_{p d, t+1}, \epsilon_{z, t+1}\right) .
\end{aligned}
$$

As discussed earlier, we estimate a nonlinear function for expected stock market returns as a function of the price-dividend ratio as the $z_{t}$ state variable for the habit formation and prospect theory models. We use a kernel regression of returns on the lagged price-dividend ratio with 100,000 years of simulated data from the models to estimate a function $f\left(p_{t}-d_{t}\right)$. For specifications that include the historical data, we find the fitted values of the function (i.e., the model-implied expected stock return) at the historical price-dividend ratios. The kernel regression estimates a function $f\left(p_{t}-d_{t}\right)$ over the range of price-dividend ratios observed in the model. For the years in which the historical price-dividend ratio was not in this range, we set $z_{t}$ equal to the closest endpoint of the function. The $z_{t}$ state variables for the habit formation and prospect theory models are shown in Figure A.1. Both models produce evidence that expected log market returns are monotonically decreasing in the log price-dividend ratio but that the relation is not linear.

Table A.1 presents the results from predictive regressions of log market returns on the modelspecific state variables. The predictive regressions use 100,000 years of simulated data from the models. Panel A reports estimates for the long-run risk model, Panel B shows results for the habit formation model, and Panel $\mathrm{C}$ presents estimates corresponding to the prospect theory model. Each panel shows regressions of market returns on each of the state variables individually as well as a specification with both variables. The results in Panel A show that including both the pricedividend ratio and risk-free rate is important in the long-run risk model. The regression $R^{2}$ in the individual state variable specifications are $0.3 \%$ and $1.3 \%$ for the price-dividend ratio and risk-free rate, respectively. The $R^{2}$ increases to $5.3 \%$ when both state variables are included. 
Returns in the habit formation model are negatively forecasted by the price-dividend ratio when it is included in isolation and the regression $R^{2}$ is $3.5 \%$ as shown in Panel $\mathrm{B}^{2}$ Introducing the $z_{t}$ state variable makes the price-dividend ratio insignificant, whereas the $z_{t}$ variable is a significant predictor of returns. The regression $R^{2}$ increases to $3.7 \%$ when the $z_{t}$ variable is included, such that the model fit improves with the nonlinear predictor. Similarly, Panel C presents results for the prospect theory model that support the importance of nonlinearities in the model. The fit of the predictive regression improves when the $z_{t}$ variable is included, and introducing the nonlinear function eliminates the predictive ability of the price-dividend ratio.

\section{B Components of Long-Horizon Variance}

\section{B.1 Derivation of Equation (4)}

Define

$$
\begin{aligned}
a_{x} & \equiv\left[\begin{array}{l}
a_{p d} \\
a_{z}
\end{array}\right], \\
b_{r} & \equiv\left[\begin{array}{ll}
b_{r, p d} & b_{r, z}
\end{array}\right], \\
B_{x} & \equiv\left[\begin{array}{ll}
b_{p d, p d} & b_{p d, z} \\
b_{z, p d} & b_{z, z}
\end{array}\right], \\
x_{t} & \equiv\left[\begin{array}{c}
p_{t}-d_{t} \\
z_{t}
\end{array}\right], \\
\epsilon_{x, t} & \equiv\left[\begin{array}{c}
\epsilon_{p d, t} \\
\epsilon_{z, t}
\end{array}\right],
\end{aligned}
$$

and

$$
\tilde{\Sigma} \equiv\left[\begin{array}{cc}
\sigma_{r}^{2} & \Sigma_{r x} \\
\Sigma_{x r} & \Sigma_{x}
\end{array}\right] .
$$

\footnotetext{
${ }^{2}$ We note that the predictive regression $R^{2}$ in the habit formation model in Table A.1 is relatively low compared to some reported values in the literature. We follow Wachter (2005) to simulate from the model, and introducing a finer grid over habit levels to accurately solve for the price-dividend ratio reduces the volatility of the price-dividend ratio and the predictive regression $R^{2}$.
} 
We can write then the asset return $r_{T+k}$ as

$$
r_{T+k}=a_{r}+b_{r}\left(I-B_{x}\right)^{-1}\left(I-B_{x}^{k-1}\right) a_{x}+b_{r} B_{x}^{k-1} x_{T}+\sum_{i=1}^{k-1} b_{r} B_{x}^{i-1} \epsilon_{x, T+k-i}+\epsilon_{r, T+k}
$$

and the cumulative return (with only the relevant terms for $\operatorname{Var}\left(r_{T, T+K} \mid \theta, D_{T}\right)$ ) as

$$
r_{T, T+k}=\ldots+\sum_{i=1}^{k-1} b_{r}\left(I-B_{x}\right)^{-1}\left(I-B_{x}^{i}\right) \epsilon_{x, T+k-i}+\sum_{i=1}^{k} \epsilon_{r, T+i}
$$

with variance

$$
\begin{aligned}
\operatorname{Var}\left(r_{T, T+k} \mid \theta\right) & =k \sigma_{r}^{2}+\sum_{i=1}^{k-1} 2 b_{r}\left(I-B_{x}\right)^{-1}\left(I-B_{x}^{i}\right) \Sigma_{x r} \\
& +\sum_{i=1}^{k-1}\left(b_{r}\left(I-B_{x}\right)^{-1}\left(I-B_{x}^{i}\right)\right) \Sigma_{x}\left(b_{r}\left(I-B_{x}\right)^{-1}\left(I-B_{x}^{i}\right)\right)^{\prime} .
\end{aligned}
$$

\section{B.2 Derivation of Equation (7)}

The expected long-horizon return is given by

$$
\mathrm{E}\left(r_{T, T+k} \mid \theta, x_{T}\right)=\mathrm{E}\left(r_{T+1}+\ldots+r_{T+k} \mid \theta, x_{T}\right),
$$

and the single-period expected returns are given by

$$
\mathrm{E}\left(r_{T+k} \mid \theta, x_{T}\right)=a_{r}+b_{r}\left(I-B_{x}\right)^{-1}\left(I-B_{x}^{k-1}\right) a_{x}+b_{r} B_{x}^{k-1} x_{T} .
$$

Summing the expected returns together produces Equation (7),

$$
\mathrm{E}\left(r_{T, T+k} \mid \theta, x_{T}\right)=k a_{r}+b_{r}\left(I-B_{x}\right)^{-1}\left(\left(k I-\left(I-B_{x}\right)^{-1}\left(I-B_{x}^{k}\right)\right) a_{x}+\left(I-B_{x}^{k}\right) x_{T}\right) .
$$

\section{B.3 Decomposing predictive return variance}

Given the return approximation in Equation (A.2), the cumulative stock market return over a horizon of $k$ years can be expressed as

$$
r_{T, T+k}=\left(p_{T+k}-d_{T+k}\right)-\left(p_{T}-d_{T}\right)+\sum_{i=1}^{k}(1-\rho)\left(d_{T+i}-p_{T+i}\right)+\Delta d_{T, T+k}+k q .
$$


Returns thus have three components that contribute to uncertainty. First, the difference between beginning and terminal price-dividend ratios, $\left(p_{T+k}-d_{T+k}\right)-\left(p_{T}-d_{T}\right)$, measures the effect of the change in market valuation on realized returns. Second, the $\sum_{i=1}^{k}(1-\rho)\left(d_{T+i}-p_{T+i}\right)$ term measures the cumulative effect on returns of the dividends that are received during the holding period. Third, $\Delta d_{T, T+k}$ is the cumulative dividend growth that is realized over the $k$-year holding period. Based on these three components, we decompose predictive return variance as follows:

$$
\begin{aligned}
\operatorname{Var}\left(r_{T, T+k} \mid D_{T}\right) & =\operatorname{Var}\left(p_{T+k}-d_{T+k} \mid D_{T}\right)+\operatorname{Var}\left(\sum_{i=1}^{k}(1-\rho)\left(d_{T+i}-p_{T+i}\right) \mid D_{T}\right) \\
& +\operatorname{Var}\left(\Delta d_{T, T+k} \mid D_{T}\right)+2 \operatorname{Cov}\left(p_{T+k}-d_{T+k}, \sum_{i=1}^{k}(1-\rho)\left(d_{T+i}-p_{T+i}\right) \mid D_{T}\right) \\
& +2 \operatorname{Cov}\left(p_{T+k}-d_{T+k}, \Delta d_{T, T+k} \mid D_{T}\right) \\
& +2 \operatorname{Cov}\left(\sum_{i=1}^{k}(1-\rho)\left(d_{T+i}-p_{T+i}\right), \Delta d_{T, T+k} \mid D_{T}\right) .
\end{aligned}
$$


Each of the predictive variances and covariances in Equation (B.14) can be decomposed as follows:

$$
\begin{aligned}
& \operatorname{Var}\left(p_{T+k}-d_{T+k} \mid D_{T}\right)=\mathrm{E}\left(\operatorname{Var}\left(p_{T+k}-d_{T+k} \mid \theta, D_{T}\right) \mid D_{T}\right) \\
& +\operatorname{Var}\left(\mathrm{E}\left(p_{T+k}-d_{T+k} \mid \theta, D_{T}\right) \mid D_{T}\right), \\
& \operatorname{Var}\left(\sum_{i=1}^{k}(1-\rho)\left(d_{T+i}-p_{T+i}\right) \mid D_{T}\right)=\mathrm{E}\left(\operatorname{Var}\left(\sum_{i=1}^{k}(1-\rho)\left(d_{T+i}-p_{T+i}\right) \mid \theta, D_{T}\right) \mid D_{T}\right) \\
& +\operatorname{Var}\left(\mathrm{E}\left(\sum_{i=1}^{k}(1-\rho)\left(d_{T+i}-p_{T+i}\right) \mid \theta, D_{T}\right) \mid D_{T}\right) \\
& \operatorname{Var}\left(\Delta d_{T, T+k} \mid D_{T}\right)=\mathrm{E}\left(\operatorname{Var}\left(\Delta d_{T, T+k} \mid \theta, D_{T}\right) \mid D_{T}\right) \\
& +\operatorname{Var}\left(\mathrm{E}\left(\Delta d_{T, T+k} \mid \theta, D_{T}\right) \mid D_{T}\right), \\
& \operatorname{Cov}\left(p_{T+k}-d_{T+k}, \sum_{i=1}^{k}(1-\rho)\left(d_{T+i}-p_{T+i}\right) \mid D_{T}\right)=\mathrm{E}\left(\operatorname { C o v } \left(p_{T+k}-d_{T+k}\right.\right. \\
& \left.\left.\sum_{i=1}^{k}(1-\rho)\left(d_{T+i}-p_{T+i}\right) \mid \theta, D_{T}\right) \mid D_{T}\right) \\
& +\operatorname{Cov}\left(\mathrm{E}\left(p_{T+k}-d_{T+k} \mid \theta, D_{T}\right)\right. \\
& \left.\mathrm{E}\left(\sum_{i=1}^{k}(1-\rho)\left(d_{T+i}-p_{T+i}\right) \mid \theta, D_{T}\right) \mid D_{T}\right) \\
& \operatorname{Cov}\left(p_{T+k}-d_{T+k}, \Delta d_{T, T+k} \mid D_{T}\right)=\mathrm{E}\left(\operatorname{Cov}\left(p_{T+k}-d_{T+k}, \Delta d_{T, T+k} \mid \theta, D_{T}\right) \mid D_{T}\right) \\
& +\operatorname{Cov}\left(\mathrm{E}\left(p_{T+k}-d_{T+k} \mid \theta, D_{T}\right)\right. \\
& \left.\mathrm{E}\left(\Delta d_{T, T+k} \mid \theta, D_{T}\right) \mid D_{T}\right), \\
& \operatorname{Cov}\left(\Delta d_{T, T+k}, \sum_{i=1}^{k}(1-\rho)\left(d_{T+i}-p_{T+i}\right) \mid D_{T}\right)=\mathrm{E}\left(\operatorname { C o v } \left(\Delta d_{T, T+k},\right.\right. \\
& \left.\left.\sum_{i=1}^{k}(1-\rho)\left(d_{T+i}-p_{T+i}\right) \mid \theta, D_{T}\right) \mid D_{T}\right) \\
& +\operatorname{Cov}\left(\mathrm{E}\left(\Delta d_{T, T+k} \mid \theta, D_{T}\right),\right. \\
& \left.\mathrm{E}\left(\sum_{i=1}^{k}(1-\rho)\left(d_{T+i}-p_{T+i}\right) \mid \theta, D_{T}\right) \mid D_{T}\right) \text {. }
\end{aligned}
$$


The variances and expectations conditional on $\theta$ and $D_{T}$ are given by:

$$
\begin{aligned}
\operatorname{Var}\left(p_{T+k}-d_{T+k} \mid \theta, D_{T}\right) & =\sigma_{p d}^{2}+\sum_{i=1}^{k-1}\left(b_{p d} B_{x}^{i-1}\right) \Sigma_{x}\left(b_{p d} B_{x}^{i-1}\right)^{\prime}, \\
\operatorname{Var}\left(\sum_{i=1}^{k}(1-\rho)\left(d_{T+i}-p_{T+i}\right) \mid \theta, D_{T}\right) & =(1-\rho)^{2}\left(k \sigma_{p d}^{2}+\sum_{i=1}^{k-1} 2 b_{p d}\left(I-B_{x}\right)^{-1}\left(I-B_{x}^{i}\right) \Sigma_{x p d}\right. \\
& \left.+\sum_{i=1}^{k-1}\left(b_{p d}\left(I-B_{x}\right)^{-1}\left(I-B_{x}^{i}\right)\right) \Sigma_{x}\left(b_{p d}\left(I-B_{x}\right)^{-1}\left(I-B_{x}^{i}\right)\right)^{\prime}\right), \\
\operatorname{Var}\left(\Delta d_{T, T+k} \mid \theta\right) & =k \sigma_{d}^{2}+\sum_{i=1}^{k-1} 2 b_{d}\left(I-B_{x}\right)^{-1}\left(I-B_{x}^{i}\right) \Sigma_{x d} \\
& +\sum_{i=1}^{k-1}\left(b_{d}\left(I-B_{x}\right)^{-1}\left(I-B_{x}^{i}\right)\right) \Sigma_{x}\left(b_{d}\left(I-B_{x}\right)^{-1}\left(I-B_{x}^{i}\right)\right)^{\prime}
\end{aligned}
$$

and

$$
\begin{aligned}
\mathrm{E}\left(p_{T+k}-d_{T+k} \mid \theta, D_{T}\right) & =a_{p d}+b_{p d}\left(I-B_{x}\right)^{-1}\left(I-B_{x}^{k-1}\right) a_{x}+b_{p d} B_{x}^{k-1} x_{T} \\
\mathrm{E}\left(\sum_{i=1}^{k}(1-\rho)\left(d_{T+i}-p_{T+i}\right) \mid \theta, D_{T}\right) & =-(1-\rho)\left(k a_{p d}+b_{p d}\left(I-B_{x}\right)^{-1}((k I\right. \\
& \left.\left.\left.-\left(I-B_{x}\right)^{-1}\left(I-B_{x}^{k}\right)\right) a_{x}+\left(I-B_{x}^{k}\right) x_{T}\right)\right) \\
\mathrm{E}\left(\Delta d_{T, T+k} \mid \theta, x_{T}\right) & =k a_{d}+b_{d}\left(I-B_{x}\right)^{-1}((k I \\
& \left.\left.-\left(I-B_{x}\right)^{-1}\left(I-B_{x}^{k}\right)\right) a_{x}+\left(I-B_{x}^{k}\right) x_{T}\right)
\end{aligned}
$$


Finally, the covariances conditional on $\theta$ and $D_{T}$ are given by:

$$
\begin{aligned}
\operatorname{Cov}\left(p_{T+k}-d_{T+k}, \sum_{i=1}^{k}(1-\rho)\left(d_{T+i}-p_{T+i}\right) \mid \theta, D_{T}\right) & =-(1-\rho)\left(\sigma_{p d}^{2}+\sum_{i=1}^{k-1} b_{p d} B_{x}^{i-1} \Sigma_{x p d}\right. \\
& \left.+\sum_{i=1}^{k-1}\left(b_{p d} B_{x}^{i-1}\right) \Sigma_{x}\left(b_{p d}\left(I-B_{x}\right)^{-1}\left(I-B_{x}^{i}\right)\right)^{\prime}\right), \\
\text { (B.27) } & \\
\operatorname{Cov}\left(p_{T+k}-d_{T+k}, \Delta d_{T, T+k} \mid \theta, D_{T}\right) & =\sigma_{d p d}+\sum_{i=1}^{k-1} b_{p d} B_{x}^{i-1} \Sigma_{x d} \\
& +\sum_{i=1}^{k-1}\left(b_{d}\left(I-B_{x}\right)^{-1}\left(I-B_{x}^{i}\right)\right) \Sigma_{x}\left(b_{p d} B_{x}^{i-1}\right)^{\prime}, \\
\operatorname{Cov}\left(\Delta d_{T, T+k}, \sum_{i=1}^{k}(1-\rho)\left(d_{T+i}-p_{T+i}\right) \mid \theta, D_{T}\right) & =-(1-\rho)\left(k \sigma_{d p d}\right. \\
& +\sum_{i=1}^{k-1} b_{p d}\left(I-B_{x}\right)^{-1}\left(I-B_{x}^{i}\right) \Sigma_{x d} \\
& +\sum_{i=1}^{k-1} b_{d}\left(I-B_{x}\right)^{-1}\left(I-B_{x}^{i}\right) \Sigma_{x p d} \\
& +\sum_{i=1}^{k-1}\left(\left(b_{p d}\left(I-B_{x}\right)^{-1}\left(I-B_{x}^{i}\right)\right) \Sigma_{x}\right. \\
& \left.\left.\times\left(b_{d}\left(I-B_{x}\right)^{-1}\left(I-B_{x}^{i}\right)\right)^{\prime}\right)\right) .
\end{aligned}
$$

\section{Alternative Specifications}

This appendix contains results on predictive return variance under alternative VAR specifications. Specifically, we examine the robustness of our main findings to (i) removing the nonnegativity constraint on the equity premium and (ii) using the model-implied risk-free rate in the implementation of the nonnegativity constraint for the habit formation and prospect theory priors. The tables in this appendix correspond to Panel $\mathrm{C}$ of Tables 1 to 3 and the figures correspond to Figure 2 in the paper.

Tables C.1 to C.3 show parameter estimates for VARs estimated with model-based priors from 
the long-run risk, habit formation, and prospect theory priors, respectively. The equity premium is not constrained to be nonnegative in the estimation. Figure C.1 shows the predictive return variance and its components associated with these VARs. Results are generally similar to our base case, as the habit formation and prospect theory investors perceive stocks to be quite safe over long horizons, whereas the long-run risk investors believe that stocks have similar risk levels over short and long holding periods. The nonnegativity constraint causes the long-run risk investor to infer a relatively lower predictability coefficient on the price-dividend ratio, which reduces the magnitudes of the mean reversion and uncertainty about future expected return components.

Tables C.4 to C.5 and Figure C.2 present results for the habit formation and prospect theory models that use the model-implied risk-free rate in the nonnegativity constraint. Both models imply a constant risk-free rate, and we implement the constraint by rejecting any posterior draw that produces a negative difference between the expected stock return implied by the VAR and the model-implied risk-free rate. The implied annual real risk-free rate for the prospect theory model is relatively high at about $3.8 \%$, such that using this risk-free rate in the constraint produces a relatively tighter constraint. Posterior draws that imply substantial time variation in expected stock returns are more likely to violate the constraint, such that the components of predictive return variance related to mean reversion and uncertainty about future expected returns are somewhat muted in this specification relative to the base case. 
Table A.1

Market return predictability regressions for simulated model data

\begin{tabular}{|c|c|c|c|}
\hline \multicolumn{4}{|c|}{ Panel A: Long-run risk model } \\
\hline $\begin{array}{c}\text { Intercept } \\
0.18 \\
(0.01)\end{array}$ & $\begin{array}{c}p_{t}-d_{t} \\
-0.04 \\
(0.00)\end{array}$ & $z_{t}$ & $\begin{array}{c}R^{2} \\
0.003\end{array}$ \\
\hline $\begin{array}{c}0.05 \\
(0.00)\end{array}$ & & $\begin{array}{l}1.90 \\
(0.05)\end{array}$ & 0.013 \\
\hline $\begin{array}{c}0.65 \\
(0.01)\end{array}$ & $\begin{array}{l}-0.21 \\
(0.00)\end{array}$ & $\begin{array}{c}5.37 \\
(0.07)\end{array}$ & 0.053 \\
\hline \multicolumn{4}{|c|}{ Panel B: Habit formation model } \\
\hline $\begin{array}{c}\text { Intercept } \\
0.59 \\
(0.01)\end{array}$ & $\begin{array}{c}p_{t}-d_{t} \\
-0.16 \\
(0.00)\end{array}$ & $z_{t}$ & $\begin{array}{c}R^{2} \\
0.035\end{array}$ \\
\hline $\begin{array}{l}-0.00 \\
(0.00)\end{array}$ & & $\begin{array}{c}1.01 \\
(0.02)\end{array}$ & 0.037 \\
\hline $\begin{array}{l}-0.11 \\
(0.10)\end{array}$ & $\begin{array}{c}0.03 \\
(0.03)\end{array}$ & $\begin{array}{c}1.24 \\
(0.17)\end{array}$ & 0.037 \\
\hline \multicolumn{4}{|c|}{ Panel C: Prospect theory model } \\
\hline $\begin{array}{c}\text { Intercept } \\
0.75 \\
(0.02)\end{array}$ & $\begin{array}{c}p_{t}-d_{t} \\
-0.22 \\
(0.01)\end{array}$ & $z_{t}$ & $\begin{array}{c}R^{2} \\
0.021\end{array}$ \\
\hline $\begin{array}{l}-0.00 \\
(0.00)\end{array}$ & & $\begin{array}{c}1.01 \\
(0.02)\end{array}$ & 0.023 \\
\hline $\begin{array}{l}-0.16 \\
(0.10)\end{array}$ & $\begin{array}{c}0.04 \\
(0.03)\end{array}$ & $\begin{array}{l}1.32 \\
(0.15)\end{array}$ & 0.023 \\
\hline
\end{tabular}

The table reports estimates from market return predictability regressions. Panel A presents estimates for the long-run risk model, Panel B shows results for the habit formation model, and Panel C displays estimates for the prospect theory model. Each regression uses 100,000 years of simulated data from the model. Each panel has predictive regressions using the price-dividend ratio and the model-specific $z_{t}$ state variables individually and in combination. The $z_{t}$ state variable is the risk-free rate for the long-run risk model and fitted expected returns as described in Online Appendix A for the habit formation and prospect theory models. For each regression, we report the coefficient estimates, standard errors, and regression $R^{2}$. 
Table C.1

Long-run risk model VAR parameter estimates-No nonnegativity constraint

\begin{tabular}{|c|c|c|c|c|c|c|c|c|}
\hline \multicolumn{9}{|c|}{ Data with model-based prior } \\
\hline \multicolumn{4}{|c|}{ VAR coefficients } & \multicolumn{5}{|c|}{ Covariance/correlation matrix } \\
\hline \multirow{3}{*}{$r_{t+1}$} & Intercept & $p_{t}-d_{t}$ & $z_{t}$ & & $r_{t+1}$ & $\Delta d_{t+1}$ & $p_{t+1}-d_{t+1}$ & $z_{t+1}$ \\
\hline & 0.22 & -0.05 & 0.68 & $r_{t+1}$ & 0.04 & 0.01 & 0.03 & 0.00 \\
\hline & $(0.10)$ & $(0.03)$ & $(0.31)$ & & $(0.00)$ & $(0.00)$ & $(0.00)$ & $(0.00)$ \\
\hline \multirow[t]{2}{*}{$\Delta d_{t+1}$} & -0.33 & 0.11 & 0.09 & $\Delta d_{t+1}$ & 0.44 & 0.02 & -0.01 & 0.00 \\
\hline & $(0.07)$ & $(0.02)$ & $(0.22)$ & & $(0.05)$ & $(0.00)$ & $(0.00)$ & $(0.00)$ \\
\hline \multirow[t]{2}{*}{$p_{t+1}-d_{t+1}$} & 0.40 & 0.87 & 0.61 & $p_{t+1}-d_{t+1}$ & 0.73 & -0.29 & 0.03 & -0.00 \\
\hline & $(0.09)$ & $(0.03)$ & $(0.30)$ & & $(0.03)$ & $(0.06)$ & $(0.00)$ & $(0.00)$ \\
\hline \multirow[t]{2}{*}{$z_{t+1}$} & 0.01 & -0.00 & 0.65 & $z_{t+1}$ & 0.01 & 0.03 & -0.02 & 0.00 \\
\hline & $(0.01)$ & $(0.00)$ & $(0.05)$ & & $(0.06)$ & $(0.06)$ & $(0.06)$ & $(0.00)$ \\
\hline
\end{tabular}

The table reports the posterior means and standard deviations of the parameters for the long-run risk VARs. The VAR specification is given in Equation (1), and the $z_{t}$ state variable is the riskfree rate as implied by the long-run risk model. The VAR is estimated without a prior that the market risk premium is positive. The table shows the VAR posteriors using the model-based prior beliefs. The covariance/correlation matrix contains variances along the diagonal and covariances (correlations) in the upper-right (lower-left) portion of the matrix. The long-run risk model is calibrated following Bansal, Kiku, and Yaron (2012). The sample period is 1872 to 2012.

Table C.2

Habit formation model VAR parameter estimates-No nonnegativity constraint

\begin{tabular}{|c|c|c|c|c|c|c|c|c|}
\hline \multicolumn{9}{|c|}{ Data with model-based prior } \\
\hline \multicolumn{4}{|c|}{ VAR coefficients } & \multicolumn{5}{|c|}{ Covariance/correlation matrix } \\
\hline \multirow{3}{*}{$r_{t+1}$} & Intercept & $p_{t}-d_{t}$ & $z_{t}$ & & $r_{t+1}$ & $\Delta d_{t+1}$ & $p_{t+1}-d_{t+1}$ & $z_{t+1}$ \\
\hline & 0.17 & -0.04 & 0.30 & $r_{t+1}$ & 0.03 & 0.01 & 0.02 & -0.00 \\
\hline & $(0.31)$ & $(0.08)$ & $(0.71)$ & & $(0.00)$ & $(0.00)$ & $(0.00)$ & $(0.00)$ \\
\hline \multirow[t]{2}{*}{$\Delta d_{t+1}$} & -0.08 & 0.04 & -0.37 & $\Delta d_{t+1}$ & 0.46 & 0.01 & -0.00 & 0.00 \\
\hline & $(0.21)$ & $(0.06)$ & $(0.48)$ & & $(0.05)$ & $(0.00)$ & $(0.00)$ & $(0.00)$ \\
\hline \multirow[t]{2}{*}{$p_{t+1}-d_{t+1}$} & 0.09 & 0.96 & 0.70 & $p_{t+1}-d_{t+1}$ & 0.75 & -0.24 & 0.03 & -0.00 \\
\hline & $(0.30)$ & $(0.08)$ & $(0.68)$ & & $(0.03)$ & $(0.06)$ & $(0.00)$ & $(0.00)$ \\
\hline \multirow{2}{*}{$z_{t+1}$} & 0.04 & -0.01 & 0.80 & $z_{t+1}$ & -0.73 & 0.19 & -0.94 & 0.00 \\
\hline & $(0.04)$ & $(0.01)$ & $(0.08)$ & & $(0.03)$ & $(0.06)$ & $(0.01)$ & $(0.00)$ \\
\hline
\end{tabular}

The table reports the posterior means and standard deviations of the parameters for the habit formation VARs. The VAR specification is given in Equation (1), and the $z_{t}$ state variable is the fitted expected return implied by the habit formation model. The VAR is estimated without a prior that the market risk premium is positive. The table shows the VAR posteriors using the modelbased prior beliefs. The covariance/correlation matrix contains variances along the diagonal and covariances (correlations) in the upper-right (lower-left) portion of the matrix. The habit formation model is calibrated following Campbell and Cochrane (1999). The sample period is 1872 to 2012. 
Table C.3

Prospect theory model VAR parameter estimates-No nonnegativity constraint

\begin{tabular}{|c|c|c|c|c|c|c|c|c|}
\hline \multicolumn{9}{|c|}{ Data with model-based prior } \\
\hline \multicolumn{4}{|c|}{ VAR coefficients } & \multicolumn{5}{|c|}{ Covariance/correlation matrix } \\
\hline \multirow{3}{*}{$r_{t+1}$} & Intercept & $p_{t}-d_{t}$ & $z_{t}$ & & $r_{t+1}$ & $\Delta d_{t+1}$ & $p_{t+1}-d_{t+1}$ & $z_{t+1}$ \\
\hline & $0.06^{2}$ & -0.01 & 0.67 & $r_{t+1}$ & 0.03 & 0.01 & 0.02 & -0.00 \\
\hline & $(0.21)$ & $(0.06)$ & $(0.57)$ & & $(0.00)$ & $(0.00)$ & $(0.00)$ & $(0.00)$ \\
\hline \multirow[t]{2}{*}{$\Delta d_{t+1}$} & -0.02 & 0.03 & -0.65 & $\Delta d_{t+1}$ & 0.60 & 0.01 & -0.00 & -0.00 \\
\hline & $(0.14)$ & $(0.04)$ & $(0.36)$ & & $(0.04)$ & $(0.00)$ & $(0.00)$ & $(0.00)$ \\
\hline \multirow[t]{2}{*}{$p_{t+1}-d_{t+1}$} & -0.08 & 1.00 & 1.38 & $p_{t+1}-d_{t+1}$ & 0.77 & -0.04 & 0.02 & -0.00 \\
\hline & $(0.18)$ & $(0.05)$ & $(0.47)$ & & $(0.02)$ & $(0.06)$ & $(0.00)$ & $(0.00)$ \\
\hline \multirow[t]{2}{*}{$z_{t+1}$} & 0.08 & -0.02 & 0.60 & $z_{t+1}$ & -0.75 & -0.16 & -0.82 & 0.00 \\
\hline & $(0.03)$ & $(0.01)$ & $(0.07)$ & & $(0.03)$ & $(0.06)$ & $(0.02)$ & $(0.00)$ \\
\hline
\end{tabular}

The table reports the posterior means and standard deviations of the parameters for the prospect theory VARs. The VAR specification is given in Equation (1), and the $z_{t}$ state variable is the fitted expected return implied by the prospect theory model. The VAR is estimated without a prior that the market risk premium is positive. The table shows the VAR posteriors using the model-based prior beliefs. The covariance/correlation matrix contains variances along the diagonal and covariances (correlations) in the upper-right (lower-left) portion of the matrix. The prospect theory model is calibrated following Barberis, Huang, and Santos (2001). The sample period is 1872 to 2012 . 
Table C.4

Habit formation model VAR parameter estimates-Alternative risk-free rate in the nonnegativity constraint

\begin{tabular}{|c|c|c|c|c|c|c|c|c|}
\hline \multicolumn{9}{|c|}{ Data with model-based prior } \\
\hline \multicolumn{4}{|c|}{ VAR coefficients } & \multicolumn{5}{|c|}{ Covariance/correlation matrix } \\
\hline \multirow{3}{*}{$r_{t+1}$} & Intercept & $p_{t}-d_{t}$ & $z_{t}$ & & $r_{t+1}$ & $\Delta d_{t+1}$ & $p_{t+1}-d_{t+1}$ & $z_{t+1}$ \\
\hline & -0.00 & 0.01 & 0.77 & $r_{t+1}$ & 0.03 & 0.00 & 0.03 & -0.00 \\
\hline & $(0.18)$ & $(0.05)$ & $(0.47)$ & & $(0.00)$ & $(0.00)$ & $(0.00)$ & $(0.00)$ \\
\hline \multirow[t]{2}{*}{$\Delta d_{t+1}$} & 0.27 & -0.04 & -1.44 & $\Delta d_{t+1}$ & 0.11 & 0.01 & -0.01 & 0.00 \\
\hline & $(0.26)$ & $(0.07)$ & $(0.65)$ & & $(0.09)$ & $(0.00)$ & $(0.00)$ & $(0.00)$ \\
\hline \multirow{2}{*}{$p_{t+1}-d_{t+1}$} & -0.45 & 1.10 & 2.29 & $p_{t+1}-d_{t+1}$ & 0.83 & -0.46 & 0.04 & -0.00 \\
\hline & $(0.32)$ & $(0.08)$ & $(0.82)$ & & $(0.03)$ & $(0.07)$ & $(0.01)$ & $(0.00)$ \\
\hline \multirow[t]{2}{*}{$z_{t+1}$} & 0.11 & -0.03 & 0.57 & $z_{t+1}$ & -0.79 & 0.42 & -0.94 & 0.00 \\
\hline & $(0.04)$ & $(0.01)$ & $(0.10)$ & & $(0.03)$ & $(0.07)$ & $(0.01)$ & $(0.00)$ \\
\hline
\end{tabular}

The table reports the posterior means and standard deviations of the parameters for the habit formation VARs. The VAR specification is given in Equation (1), and the $z_{t}$ state variable is the fitted expected return implied by the habit formation model. The VAR is estimated using a prior that the market risk premium is positive, and the risk-free rate used in the risk premium calculation is the constant risk-free rate implied by the habit formation model. The table shows the VAR posteriors using the model-based prior beliefs. The covariance/correlation matrix contains variances along the diagonal and covariances (correlations) in the upper-right (lower-left) portion of the matrix. The habit formation model is calibrated following Campbell and Cochrane (1999). The sample period is 1872 to 2012 . 
Table C.5

Prospect theory model VAR parameter estimates-Alternative risk-free rate in the nonnegativity constraint

\begin{tabular}{|c|c|c|c|c|c|c|c|c|}
\hline \multicolumn{9}{|c|}{ Data with model-based prior } \\
\hline \multicolumn{4}{|c|}{ VAR coefficients } & \multicolumn{5}{|c|}{ Covariance/correlation matrix } \\
\hline \multirow{3}{*}{$r_{t+1}$} & Intercept & $p_{t}-d_{t}$ & $z_{t}$ & & $r_{t+1}$ & $\Delta d_{t+1}$ & $p_{t+1}-d_{t+1}$ & $z_{t+1}$ \\
\hline & 0.01 & 0.01 & 0.87 & $r_{t+1}$ & 0.03 & 0.00 & 0.03 & -0.00 \\
\hline & $(0.12)$ & $(0.03)$ & $(0.34)$ & & $(0.00)$ & $(0.00)$ & $(0.00)$ & $(0.00)$ \\
\hline \multirow[t]{2}{*}{$\Delta d_{t+1}$} & 0.11 & -0.01 & -1.30 & $\Delta d_{t+1}$ & 0.12 & 0.01 & -0.01 & 0.00 \\
\hline & $(0.15)$ & $(0.04)$ & $(0.44)$ & & $(0.09)$ & $(0.00)$ & $(0.00)$ & $(0.00)$ \\
\hline \multirow[t]{2}{*}{$p_{t+1}-d_{t+1}$} & -0.27 & 1.05 & 2.26 & $p_{t+1}-d_{t+1}$ & 0.83 & -0.45 & 0.04 & -0.00 \\
\hline & $(0.20)$ & $(0.05)$ & $(0.56)$ & & $(0.03)$ & $(0.07)$ & $(0.01)$ & $(0.00)$ \\
\hline \multirow[t]{2}{*}{$z_{t+1}$} & 0.12 & -0.03 & 0.43 & $z_{t+1}$ & -0.70 & 0.31 & -0.81 & 0.00 \\
\hline & $(0.03)$ & $(0.01)$ & $(0.08)$ & & $(0.04)$ & $(0.08)$ & $(0.03)$ & $(0.00)$ \\
\hline
\end{tabular}

The table reports the posterior means and standard deviations of the parameters for the prospect theory VARs. The VAR specification is given in Equation (1), and the $z_{t}$ state variable is the fitted expected return implied by the prospect theory model. The VAR is estimated using a prior that the market risk premium is positive, and the risk-free rate used in the risk premium calculation is the constant risk-free rate implied by the prospect theory model. The table shows the VAR posteriors using the model-based prior beliefs. The covariance/correlation matrix contains variances along the diagonal and covariances (correlations) in the upper-right (lower-left) portion of the matrix. The prospect theory model is calibrated following Barberis, Huang, and Santos (2001). The sample period is 1872 to 2012 . 

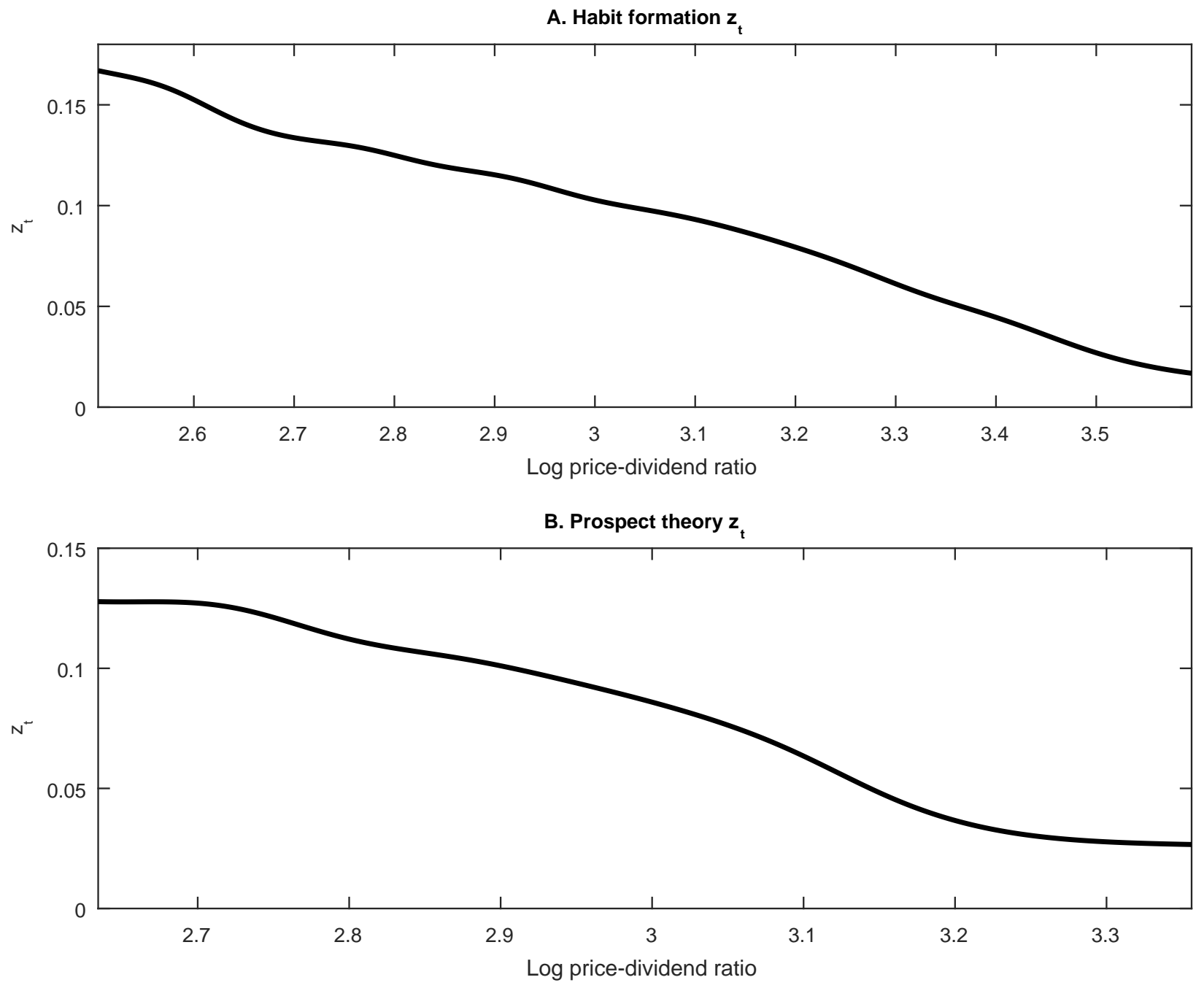

Figure A.1

Model-implied state variable for the habit formation and prospect theory models

The figure shows the model-implied $z_{t}$ state variables for the habit formation and prospect theory models. The state variable for each model is the fitted expected market return from a kernel regression of the log market return on the lagged log price-dividend ratio using 100,000 years of simulated data from the model. Panel A shows the state variable for the habit formation model and Panel B displays the state variable implied by the prospect theory model. 



Figure C.1

Predictive return variance ratio and its components by horizon using uninformative and model-based priors-No nonnegativity constraint

The figure shows predictive variance ratios for returns and the components attributable to mean reversion, uncertainty about future expected returns, and estimation risk. The thin lines correspond to the VARs estimated using uninformative priors from Panel A of Tables 1 to 3, and the thick lines are based on VARs from Panel $\mathrm{C}$ of Tables 1 to 3 that are estimated with model-based priors implied by the long-run risk, habit formation, and prospect theory models. The VARs are estimated without a prior that the market risk premium is positive. The sample period is 1872 to 2012 . 

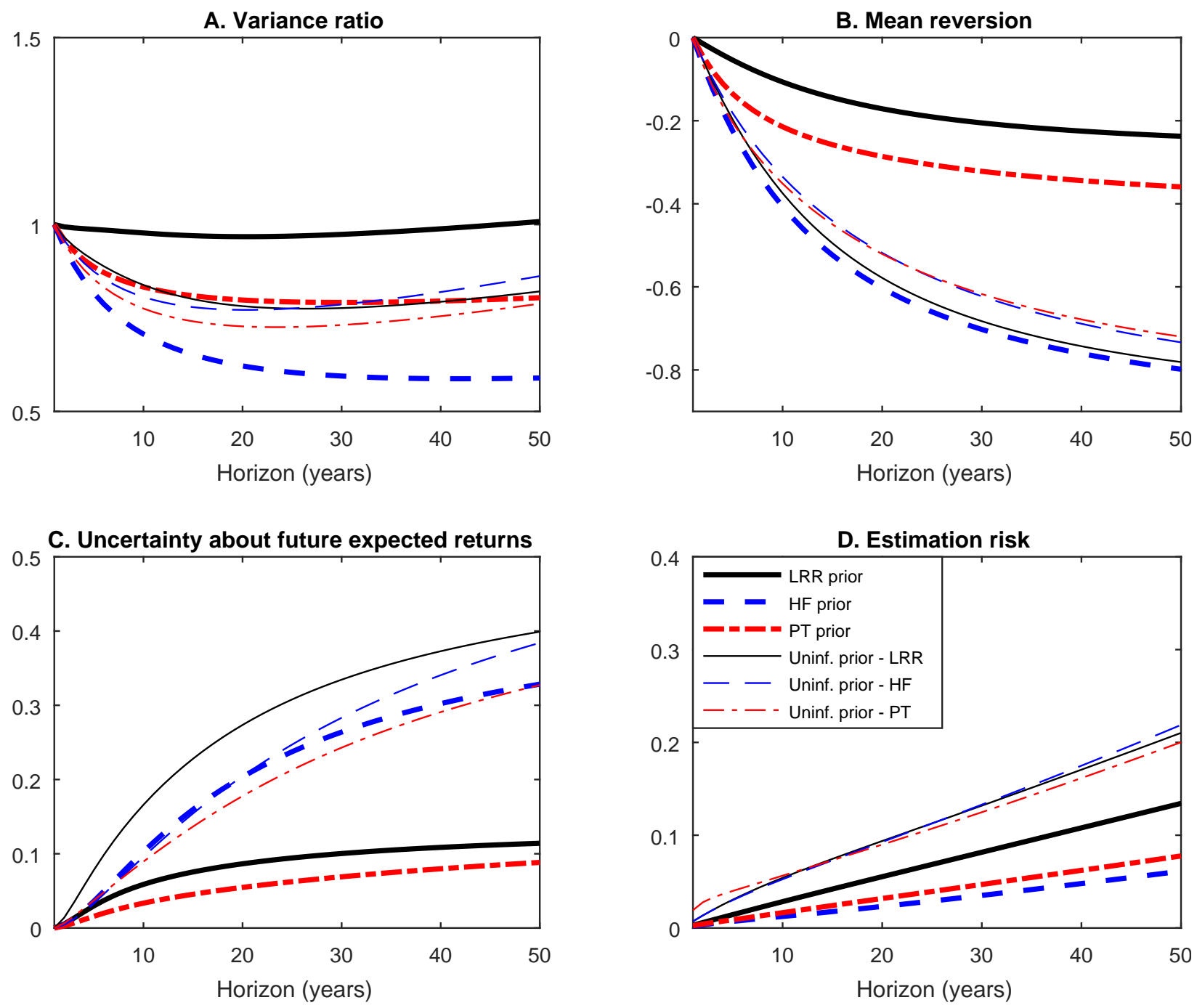

Figure C.2

Predictive return variance ratio and its components by horizon using uninformative and model-based priors-Alternative risk-free rate in the nonnegativity constraint

The figure shows predictive variance ratios for returns and the components attributable to mean reversion, uncertainty about future expected returns, and estimation risk. The thin lines correspond to the VARs estimated using uninformative priors from Panel A of Tables 1 to 3, and the thick lines are based on VARs from Panel $\mathrm{C}$ of Tables 1 to 3 that are estimated with model-based priors implied by the long-run risk, habit formation, and prospect theory models. The VAR is estimated using a prior that the market risk premium is positive, and the risk-free rates used in the risk premium calculation for the habit formation and prospect theory models are the constant risk-free rates implied by the models. The sample period is 1872 to 2012 . 